\title{
Growth Defects and Impaired Cognitive-Behavioral Abilities in Mice with Knockout for Eif4h, a Gene Located in the Mouse Homolog of the Williams- Beuren Syndrome Critical Region
}

\author{
Simona Capossela, ${ }^{*}$ Luca Muzio, ${ }^{\dagger}$ \\ Alessandro Bertolo, ${ }^{*}$ Veronica Bianchi, ${ }^{\ddagger}$ \\ Gabriele Dati, ${ }^{\S}$ Linda Chaabane, ${ }^{\S}$ Claudia Godi, ${ }^{\natural}$ \\ Letterio S. Politi," Stefano Biffo,"*** \\ Patrizia D'Adamo, ${ }^{\ddagger}$ Antonello Mallamaci, ${ }^{\dagger \dagger}$ and \\ Maria Pannese* \\ From the Gene Expression Unit, Division of Genetics and Cell \\ Biology,* the Neuroimmunology Unit - INSPE, Division of \\ Neuroscience, the Molecular Genetics of Mental Retardation \\ Unit, Division of Neuroscience, Dulbecco Telethon Institute, ${ }^{\ddagger}$ the \\ INSPE, Division of Neuroscience, "the Neuroradiology Research \\ Group, Center for Imaging, " and the Molecular Histology and \\ Cell Growth Unit, Division of Molecular Oncology, San Raffaele \\ Scientific Institute, Milan; the Department of Science of \\ Environment and Life (DISAV), ${ }^{* *}$ University of Eastern Piedmont, \\ Alessandria; and the International School for Advanced \\ Studies, ${ }^{\dagger+}$ SISSA, Trieste, Italy
}

Protein synthesis is a tightly regulated, energy-consuming process. The control of mRNA translation into protein is fundamentally important for the fine-tuning of gene expression; additionally, precise translational control plays a critical role in many cellular processes, including development, cellular growth, proliferation, differentiation, synaptic plasticity, memory, and learning. Eukaryotic translation initiation factor $4 \mathrm{~h}$ (Eif $4 \mathrm{~b}$ ) encodes a protein involved in the process of protein synthesis, at the level of initiation phase. Its human homolog, WBSCR1, maps on 7q11.23, inside the $1.6 \mathrm{Mb}$ region that is commonly deleted in patients affected by the Williams-Beuren syndrome, which is a complex neurodevelopmental disorder characterized by cardiovascular defects, cerebral dysplasias and a peculiar cognitive-behavioral profile. In this study, we generated knockout mice deficient in Eif $4 \mathrm{~b}$. These mice displayed growth retardation with a significant reduction of body weight that began from the first week of postnatal development. Neuroanatomical profiling results generated by magnetic resonance imaging analysis revealed a smaller brain volume in null mice compared with controls as well as altered brain morphology, where anterior and posterior brain regions were differentially affected. The inactivation of Eif $4 \mathrm{~b}$ also led to a reduction in both the number and complexity of neurons. Behavioral studies revealed severe impairments of fear-related associative learning and memory formation. These alterations suggest that Eif $4 b$ might contribute to certain deficits associated with Williams-Beuren syndrome. (Am J Pathol 2012, 180: 1121-1135; DOI: 10.1016/j.ajpath.2011.12.008)

Protein synthesis is an energy consuming process, tightly regulated in its three main steps: initiation, elongation, and termination. Control of translation is fundamental for fine-tuning of gene expression and plays a critical role in development, cellular growth, proliferation, differentiation, synaptic plasticity, memory and learning. In eukaryotes this process is mainly regulated at the level of initiation, when the mRNA is recruited to the small subunit of the ribosome, thanks to catalytic activities of eukaryotic translation initiation factors (elFs) of the elF4 families. ${ }^{1-3}$ In this step the $5^{\prime}$ cap structure ( $\left.{ }^{\mathrm{m} 7} \mathrm{Gpppn}\right)$ of the mRNAs is bound by elF4F, a complex composed of three proteins: elF4E the cap binding protein, elF4G a large scaffolding protein, and elF4A an ATP-dependent helicase able to unwind secondary structures in the mRNA 5'UTR, so facilitating ribosome binding. The ATPase and helicase activities of elF4A are stimulated by elF4B and

Supported by grants of Fondazione Telethon GP0080Y01, and Fondazione Mariani, R-01-23; and Compagnia di San Paolo 1438IT/ PF_2003.0031; and Ministero Istruzione Università e Ricerca FIRB RBAU01RN39 (A.M.); Fondazione Cariplo CAR0578 (S.B.); and Fondation Jérôme Lejeune (M.P.).

Accepted for publication December 2, 2011.

Supplemental material for this article can be found at http://ajp. amjpathol.org or at doi: 10.1016/j.ajpath.2011.12.008.

Current address of A.B., Swiss Paraplegic Research, Nottwil, Switzerland.

Address reprint requests to Maria Pannese, M.Sc, San Raffaele Scientific Institute, Dibit, Via Olgettina 58, 20132 Milano, Italy. E-mail: pannese. maria@hsr.it. 
elF4H, two factors that bind RNA by virtue of their N-terminal RNA recognition motifs. ${ }^{4-6}$

The human homolog of Eif4h, WBSCR1, is located in $7 q 11.23$ within a region commonly deleted in patients affected by the Williams-Beuren syndrome (WBS; OMIM 194050). WBS is classically associated to heterozygous deletions spanning a region of $1.6 \mathrm{Mb}$, containing about 28 genes. Deletions formation is mediated by low-copy repeat elements flanking the Williams-Beuren syndrome critical region that may lead to nonallelic homologous recombination, if misaligned in meiosis. ${ }^{7,8}$ This syndrome is a complex neurodevelopmental disorder including cardiovascular defects, elfin-like face, infantile hypercalcemia, cerebral dysplasias, and a peculiar cognitive-behavioral profile, ${ }^{9-12}$ and occurs at a frequency of approximately 1 in 7500 live births. ${ }^{13}$ The mouse genomic region syntenic to the human WilliamsBeuren syndrome critical region is on chromosome band $5 G 2$, in reverse orientation with respect to the centromere. ${ }^{14} \mathrm{~A}$ number of loss-of-function mouse models for single genes of this region, as well as strains with large deletions spanning the critical region have been generated and characterized. ${ }^{15}$ Whereas there is general consensus about link between Elastin (ELN) hemizygosity and occurrence of supravalvular aortic stenosis, ${ }^{16}$ more controversial is the origin of the WBS cognitive-behavioral profile.

We generated a mutant mouse line, starting from an embryonic stem cell gene-trap clone, carrying an inactivated Eif4h allele. Eif4h null mice displayed growth retardation and a generalized weight and volume decrease in the majority of organs and tissues analyzed. In vivo profiling by magnetic resonance imaging (MRI) revealed a smaller brain volume in null mice than in controls; the volumes were differently affected in the anterior and posterior brain regions, indicating altered brain morphology. Histological and cytological studies revealed a reduction in number and complexity of neurons. In addition, behavioral tests revealed severe impairments of fear-related associative learning and memory formation in the knockouts. These results demonstrated that Eifth might contribute to some deficits associated to the Williams-Beuren syndrome.

\section{Materials and Methods}

\section{Cells}

The gene trap embryonic stem cell line (Ex279, strain 129/Ola) was provided by BayGenomics (San Francisco, $\mathrm{CA}$ ) and used to produce chimeric animals by blastocyst injection techniques. Southern blot hybridization was used to identify the targeted allele in embryonic stem cell clones. Genomic DNA was extracted, digested with HindIII (Promega, Madison, WI), fractionated by agarose gel electrophoresis and transferred to hybond $\mathrm{N}^{+}(\mathrm{Am}$ ersham; GE Healthcare, Little Chalfont, UK) using alkaline transfer. The blot was hybridized with a randomlabeled probe. Germ-line chimeras were crossed to the C57BL/6 strain. Primary embryo fibroblasts (MEFs) were prepared from E14.5 embryos. In brief, embryos were dissociated by $0.05 \%$ Trypsin/0.53 mmol/L EDTA [Gibco (Life Technologies), Paisley, UK] at $37^{\circ} \mathrm{C}$ for 10 minutes and then treated with $200 \mathrm{U}$ DNasel (Tebu-Bio, Le-Perray-en-Yvelines, France). After filtering with a $70-\mu \mathrm{m}$ cell strainer, fibroblasts were cultured in DMEM (Gibco) supplemented with $10 \%$ fetal bovine serum (FBS), 2 mmol/L glutamine, $100 \mathrm{U} / \mathrm{mL}$ penicillin and $0.1 \mathrm{mg} / \mathrm{mL}$ streptomycin (Gibco). MEFs were cultured at $9 \% \mathrm{CO}_{2}$ at $37^{\circ} \mathrm{C}$. For Western blot MEFs were collected at passage P3.

\section{Animals}

Genotyping analysis of mice was performed on tail genomic DNA by PCR, using the following primers: forward 5'-GTAAACTTGAGGGTGAGGACGTGGGAGCCTGCA-3'; reverse wild type (WT) 5'-CATGAGCATGTTCTAACAAAGCCGTGTAGGTGG-3'; reverse knockout (KO) 5'-CCCAGACCTTGGGACCACCTCATCAGAAGCAG3'; PCR products length: wild-type allele $250 \mathrm{bp}$; Eif4h ${ }^{(E X 279)}$ allele $231 \mathrm{bp}$. Mice were housed in a temperature-controlled room with a 12-hour light/dark cycle and they had free access to food and water. Body weight was recorded weekly, and food intake was measured every day, at 5 to 6 months of age, for 15 consecutive days. For fertility study, mice were 8 to 16 weeks old. Males were housed in one cage with two females each one. Every morning the females were checked for the presence of vaginal plug, an indication that sexual activity had taken place. For the behavior analysis, 20 wild-type and 20 knockout mice were maintained on a reversed 12-hour dark/light cycle at $22^{\circ} \mathrm{C}$ to $25^{\circ} \mathrm{C}$ and tested at 2 to 4 months of age. For all of the experiments knockout and control animals were sex and age matched. The observers were blind to the genotype during data collection and data analysis. Experiments were done according to the animal protocols approved by the DIBIT Institutional Animal Care (Milan, Italy) and were approved by the $\mathrm{Na}$ tional Ministry of Health. All experiments were performed in accordance with the guidelines established by the European Community Council Directive of November 24, 1986 on the use of animals in research (86/609/EEC). All efforts were made to minimize animal suffering and to use only the number of animals necessary to produce reliable results.

\section{RT-PCR Assay}

Total RNA was extracted from tissue samples with Trizol Reagent (Invitrogen [Life Technologies], Paisley, UK) according to the manufactures instructions. After digestion with Dnase RNase-free (Promega, Madison, WI) for 30 minutes at $37^{\circ} \mathrm{C}$, RNA was isolated by using RNeasy Mini kit (Qiagen, Hilden, Germany). cDNA synthesis was performed using ThermoScript RT-PCR System (Invitrogen) and Random Primers (Promega). The LightCycler 480 System (Roche, Basel, Switzerland) and SYBR Green JumpStart Taq ReadyMix (Sigma-Aldrich, St. Louis, MO) were used. The primers used for the quantifications were: Eif4h forward 5'-GTCGCTTTCGAGATGGCCCTCCTCTGCGTGGC-3', reverse 5'-CCTAAGCTCATTCTTGCTCC- 
TTCTGAACCACTTC-3'; Cyln2 forward 5'-ACGGTATTCACCAGCCAGAC-3', reverse 5'-CACATCTCCAAGGGGACAGT-3'; Limk1 forward 5'-TGCTCAAGTTCATCGGAGTG-3', reverse 5-'-TTCATCGAATGGAGGTAGGC-3'; Gtf2/ forward 5'-CAATCGGATGAGTGTGGATG-3', reverse 5'-GGTTGCGAGGTCGTAATGTT-3'; Gtf2ird1 forward 5'-CCAGACAAGATCCCCTTCAA-3', reverse 5'GTCTTCTGGTGGGCTAGCTG-3'. $\beta$-actin was used as housekeeping gene: forward 5'-GACTCCTATGTGGGTGACGAGG-3'; reverse 5'-CATGGCTGGGGTGTTGAAGGTC-3'. The experiments were done in triplicate. A fold change in expression was calculated using the $2^{-\Delta \Delta C t}$ formula of the $\delta$-delta Ct method.

\section{In Situ Hybridization and X-Gal Staining}

Adult mouse brains were dissected, fixed 30 minutes in $4 \%$ paraformaldehyde in PBS, included in 5\% low melting agarose in PBS, and sectioned to $150 \mu \mathrm{m}$ by using a vibroslicer. For in situ hybridization sections were fixed overnight in $4 \%$ paraformaldehyde at $4^{\circ} \mathrm{C}$. Sense and antisense riboprobes for Eif4h and LacZ were prepared by in vitro transcription with DIG-11-UTP (DIG RNA Labeling Mix; Roche) by T3 or T7 polymerases (Promega). Sections were hybridized overnight at $60^{\circ} \mathrm{C}$ with the DIGlabeled riboprobes and visualized by alkaline phosphatase conjugated anti-DIG antibody. For X-gal staining sections were fixed 2 minutes in $4 \%$ paraformaldehyde and washed three times for 15 minutes in $0.02 \%$ PBS NP-40. They were stained overnight at room temperature in $1 \mathrm{mg} / \mathrm{mL} \mathrm{X-gal,} 5 \mathrm{mmol} / \mathrm{L} \mathrm{K}_{3} \mathrm{Fe}(\mathrm{CN})_{6}, 5 \mathrm{mmol} / \mathrm{L}$ $\mathrm{K}_{4} \mathrm{Fe}(\mathrm{CN})_{6}, 2 \mathrm{mmol} / \mathrm{L} \mathrm{MgCl}_{2}, \quad 0.01 \%$ sodium-deoxycholate, $0.02 \%$ NP-40 in PBS. After staining, sections were washed in PBS and postfixed for 5 minutes in 4\% paraformaldehyde. Sections were analyzed and photographed using a Nikon SMZ 800 stereomicroscope (Objective P-Achro 0.5X; Zoom 2X) and a Nikon DS-L1 digital camera (Nikon Corporation, Tokyo, Japan).

\section{Brain Subcellular Fractions}

Subcellular fractions were prepared from wild-type brains, dissected free from bulbs, cerebellum, and brain stem. The pool of cortical and subcortical regions $(H)$, was homogenized with ice-cold $\mathrm{H}$ buffer $(320 \mathrm{mmol} / \mathrm{L}$ sucrose, $5 \mathrm{mmol} / \mathrm{L}$ HEPES-NaOH buffer, $\mathrm{pH} 7.4,2$ $\mathrm{mmol} / \mathrm{L}$ EDTA, $0.1 \mathrm{mmol} / \mathrm{L}$ phenylmethylsulfonyl fluoride (PMSF), 1/1000 protease inhibitor), and was centrifuged for 10 minutes at $1000 \times g$ The resulting pellet (P1) was resuspended in Homogenization Buffer, while the supernatant (S1) was collected and centrifuged for 15 minutes at $10,000 \times g$. The supernatant (S2) was centrifuged for 20 minutes at $75000 \mathrm{rpm}$ in a Beckman TL100.2 rotor (Beckman Coulter, Brea, CA) to give the supernatant (S3) and the pellet (P3); while the pellet (P2) was resuspended in Homogenization Buffer and lysed with 9 volumes of HEPES $5 \mathrm{mmol} / \mathrm{L}-1 / 1000$ protease inhibitor. The suspension was kept on ice for 30 minutes and then was centrifuged for 20 minutes at $25000 \mathrm{rpm}$ in a Beckman TL100.2 rotor to yield a lysate pellet (LP1) and a lysate supernatant (LS1). The lysate supernatant was collected and centrifuged for 20 minutes at 75000 rpm in a Beckman TL100.2 rotor, to obtain the supernatant (LS2) and the pellet (LP2). The pellets (P3, LP1, and LP2) were resuspended in $\mathrm{HB}$.

\section{Western Blot}

MEFs pellet and subcellular fractions were lysated in ice-cold radioimmunoprecipitation assay buffer (50 $\mathrm{mmol} / \mathrm{L}$ TrisHCl ph7.4, $1 \%$ Triton, $0.2 \%$ sodium-deoxycholate, $0.2 \%$ SDS, $1 \mathrm{mmol} / \mathrm{L}$ EDTA, $1 \mathrm{mmol} / \mathrm{L} \mathrm{PMSF}$ ). Protein content was determined by the Bradford protein assay (Bio-Rad, Hercules, CA). Briefly, proteins were separated by SDS-polyacrylamide gel and transferred to Hybond ECL membranes (Amersham) for 1 hour at 300 $\mathrm{mA}$. The membranes were blocked for 1 hour with $5 \%$ blocking agent (milk) in Tris-buffered saline containing $0.05 \%$ Tween-20 (TBST). Membranes were incubated overnight at $4{ }^{\circ} \mathrm{C}$ with primary antibodies: elF4H (Cell Signaling, Danvers, MA) diluted 1:1000 in 5\% BSA-TBST; and ERK 2 (K-23) (Santa Cruz Biotechnology, Santa Cruz, CA) diluted 1:5000, $\beta$-Tubulin (Sigma) diluted $1: 1000$, synaptophysin $(\mathrm{p} 38)^{17}$ diluted $1: 8000$, in $5 \%$ milk-TBST. Incubation with primary antibody $\beta$-actin (Sigma), diluted 1:10,000 in TBST was performed for 2 hours at room temperature. Secondary antibodies were diluted in 5\% milk-TBST and incubated for 1 hour at room temperature. Horseradish peroxidase (HRP)-conjugated anti-rabbit antibody (Cell Signaling) diluted 1:2000 was used for elF4H; HRP-conjugated anti-mouse antibody (Amersham) diluted 1:20,000 for $\beta$-actin, and HRP-conjugated anti-rabbit and anti-mouse antibody (Amersham) diluted 1:5000 for others primary antibodies. Detection was performed with ECL plus Western blotting detection kit (Amersham).

\section{Computed Tomography Technique}

Computed tomography (CT) scans were performed on a human-grade 64-channel multislice apparatus (Light Speed VCT; GE Healthcare, Barrington, IL). The imaging protocol included a biplanar scout and a helical volumetric CT acquisition with coverage of the whole body, with a tube speed rotation of 0.5 seconds, $0.625-\mathrm{mm}$ slice thickness, and $0.3 \mathrm{~mm} / \mathrm{sec}$ table motion, $120 \mathrm{KV}, 680 \mathrm{~mA}$, reconstruction field of view of $17 \mathrm{~cm}$, and matrix of $512 \times$ 512. CT images were filtered with both the standard parenchyma and the high-resolution bone algorithms. On a dedicated workstation (Advantage 4.4; GE Healthcare) the total body, skeletal, fat and muscle volumes (in cubic centimeters) of each mouse were measured after applying an automatic segmentation (bone threshold $>160$ Hounsfield Unit; density range from -190 to -10 H.U. for fat; density range from 10 to $65 \mathrm{H} . \mathrm{U}$. for muscle). For each mouse, skull anteroposterior, nasal-zygomatic, and latero-lateral distances were measured (in centimeters) on the reformatted images. 


\section{In Vivo MRI}

Brain imaging was performed at 6 months of age on a 7T-MRI scanner (Pharmascan, Bruker, Ettlingen, Germany). High-resolution coronal sections were acquired along the brain of mice maintained under anesthesia with flurane gas mixed with $\mathrm{O}_{2}$. A multislice multiecho (MSME) sequence ( $\mathrm{TR}=3465 \mathrm{~ms}$ and $\mathrm{TE}=18$ and $44 \mathrm{~ms}$ ) with a slice thickness of $0.85 \mathrm{~mm}$ was used to generate 15 contiguous T2-weighted images with a plane spatial resolution of $86 \times 93 \mu \mathrm{m}^{2}$. For neuroanatomical analysis, the area of the measured regions was manually traced using Image J (National Institutes of Health, Bethesda, MD). The total volume of each structure was calculated by multiplying the sum of the measured areas by the slice thickness.

\section{Immunohistochemistry}

Immunohistochemistry experiments were realized on mice that were transcardially perfused with $4 \%$ paraformaldehyde (PFA). Brains were then removed, postfixed overnight in 4\% PFA, and cryoprotected in 30\% sucrose before freezing in OCT. The $10-\mu \mathrm{m}$ cryosections were cut and stored at $-80^{\circ} \mathrm{C}$. Cryosections were washed in PBS, incubated in methanol-3\% $\mathrm{H}_{2} \mathrm{O}_{2}$ to block endogenous peroxidase activity, rehydrated, and incubated for 1 hour at room temperature with blocking mix (PBS 1X/FBS 10\%/ BSA $1 \mathrm{mg} / \mathrm{mL} /$ Triton $\times 1000.1 \%)$. Sections were then incubated at $4^{\circ} \mathrm{C}$ overnight with the following primary antibodies: NeuN (Millipore, Billerica MA), myelin binding protein (Abcam, Cambridge, MA) diluted 1:500 in blocking mix. A biotin conjugated goat anti-mouse IgG secondary antibody (Vector Laboratories, Peterborough, UK) was used 1:200 for 2 hours and then sections were further incubated with avidin-biotin complex Vectastain Elite ABC Kit (Vector Laboratories) accordingly manufacture's recommendation. Signals were revealed by incubating sections in amino-9-ethyl carbazole (AEC, Sigma). Four sections, $240 \mu \mathrm{m}$ spaced each other, were used for cell counting. Images were taken by using Olympus microscope (Tokyo, Japan), magnification $\times 20$.

\section{TUNEL Assay}

For terminal deoxynucleotidyl transferase dUTP nick end labeling (TUNEL) assay, adult brain cryosections $(10 \mu \mathrm{m})$ were post fixed in $4 \%$ paraformaldehyde, incubated in methanol-3\% $\mathrm{H}_{2} \mathrm{O}_{2}$ to block endogenous peroxidase activity, and permeabilized with proteinase $\mathrm{K} 10 \mathrm{mg} / \mathrm{mL}$ for 15 minutes at room temperature. Slices were incubated with TUNEL transferase buffer for 15 minutes before adding the following reagents: 0.01 $\mathrm{mmol} / \mathrm{L}$ biotin $16 \mathrm{dUTP}, 1.25 \mathrm{mmol} / \mathrm{L} \mathrm{CoCl}_{2}$ and $80 \mathrm{U}$ of terminal transferase (Roche). Reaction was incubated 1 hour at $37^{\circ} \mathrm{C}$. Sections were incubated with avidinbiotin complex Vectastain Elite ABC Kit (Vector Laboratories) for 1 hour and stained with amino-9-ethyl carbazole (AEC, Sigma) and $\mathrm{H}_{2} \mathrm{O}_{2}$. Positive controls were obtained by incubating slices in $3 \mathrm{U} / \mathrm{mL}$ DNase for 15 minutes at room temperature.

\section{Golgi Staining}

An FD rapid Golgi staining kit (FD Neurotechnologies, Baltimore, MD) was used to stain $60 \mu \mathrm{m}$-thick brain coronal sections according to the manufacture's recommendation. Sholl analysis was done on deep cortical neurons of the posterior cortical plate. Briefly, neuron images were captured at magnification $\times 20$ and concentric circles were applied by using ImageJ software, number of intersections of dendrites, at increasing distances from the soma, were counted on each circle. Number of dendritic spines was calculated by counting the total number of spines divided by the dendritic length (10 $\mu \mathrm{m})$. Only completely impregnated dendrites within the tissue sections were used for spine counts, as previously described. ${ }^{18}$

\section{Rota-Rod Test}

The rota-rod is an apparatus composed by a horizontal rotating rod (diameter approximately $3 \mathrm{~cm}$ ) on which the mouse has to keep its balance. Five mice were simultaneously placed on the rota-rod apparatus, separated by large disks. In the accelerating rota-rod test (test 1) each mouse was subjected to five consecutive trials, with an interval of 30 minutes; 5 minutes is the maximum time for each trial. Mice were placed every trial on the rota-rod apparatus with the rod rotating at $4 \mathrm{rpm}$ (rotations/minute) during the first minute, then the rotation speed is increased every 30 seconds by $4 \mathrm{rpm}$ reaching the maximum speed of $36 \mathrm{rpm}$. A trial ended for a mouse when it fell down or when 5 minutes (300 seconds) were completed. In the constant rota-rod test of 5 minutes (test 2) all mice were tested for five consecutive trials at a constant speed, which is the average of speed reached from all mice on the accelerating test. A trial ended for a mouse when it fell down or when 5 minutes (300 seconds) were completed. Additionally, mice were tested on the rota-rod apparatus for five consecutive trials of $10 \mathrm{~min}$ utes each (test 3). Each trial consisted of 5 minutes in accelerating rotation speed every 30 seconds by 4 rpm, followed by 5 minutes at maximum constant speed. A trial ended for a mouse when it fell down or when 10 minutes (600 seconds) were completed. The latency to fall off the rod is taken as the dependent variable for every trial.

\section{Light-Dark Box}

A $20 \times 30-\mathrm{cm}$ lit chamber with transparent perspex walls (20-cm high) and open top was connected to a $20 \times$ $15 \times 20-\mathrm{cm}$ plastic dark box that was completely closed except for the $7.5 \times 7.5-\mathrm{cm}$ door connecting it to the lit chamber. Illumination was by direct room light (500 Ix). Each mouse was released in the middle of the lit compartment and observed for 5 minutes. The time spent in the dark compartment, the distance traveled, and the speed were measured. 


\section{Novelty Test}

Frames of nonreflective aluminum (37-cm high) were used to partition a round open field arena (diameter of $150-\mathrm{cm}$ and $35-\mathrm{cm}$ high walls) into four squares $50 \times$ 50-cm arenas, allowing for concurrent observation of four animals. Illumination in the room was by indirect diffuse room light ( $4 \times 40-W$ bulbs, $12 \mathrm{Ix}$ ). The novel object was a $50 \mathrm{~mL}$ Falcon tube positioned vertically in the center of the arena. Each animal was observed for 30 minutes in the empty arena as pre-exposure. The novel object was then introduced, and observation continued for another 30 minutes. For time course analysis, the total observation time was portioned into six periods of 10 minutes. The distance to the object and the locomotor activity (as distance traveled) were measured.

\section{Emergence Test}

The arena was the same of novelty test. Twenty-four hours before testing, a plastic home box $(12 \times 8 \times 4 \mathrm{~cm}$ with opening of $8 \times 4 \mathrm{~cm}$ ) was placed in the home cage of each test mouse. The next day the home box was placed in a corner of the arena, at $5 \mathrm{~cm}$ from the nearest walls, with the opening facing away from the wall. The mice were introduced into the arena and observed for 30 minutes. For time course analysis, the total observation time was portioned into three periods of 10 minutes. The percentage of the time spent inside the home box, the distance traveled and the speed were measured.

\section{Morris Water Maze}

The standard hidden-platform version of the Morris water maze was done as previously described. ${ }^{19-21}$ Mice were trained in a circular pool (150-cm diameter and $50-\mathrm{cm}$ height) according to standardized protocols. ${ }^{22}$ The wiremesh platform was $14 \times 14 \mathrm{~cm}$. In the hidden-platform version of the water maze, mice had to locate a hidden platform in a fixed position. The test included an acquisition phase (18 trials, six/day, intertrial time 30 to 40 minutes) followed by a reversal phase during which the platform was moved to the opposite position (12 trials, six/day). The first 30 seconds of trial 19 (first reversal trial) were considered as a probe trial. For the analysis the trials were averaged in blocks of two trials. The following measures were calculated: escape latency, swimming speed, floating, and wall hugging time. Spatial selectivity during the probe trial was quantified using the following parameters: percentage of time in the trained quadrant, percentage of time in a circular target zone comprising one-eighth of the pool surface and the annulus crossings. Behavioral assessment of visual acuity was performed in a modifying form of the water maze. Mice were trained in a circular pool (150-cm diameter and 50-cm height) with a $14 \times 14-\mathrm{cm}$ wire-mesh platform located in a fixed position with a flag that was visible by the mice. The test was composed by six trials of 2 minutes each. The dependent variable considered was the ability to reach the platform.

\section{Video Tracking, Data Collection, and Statistical Analysis}

For exploration tests and water maze test, animals were video-tracked using the EthoVision 2.3 system (Noldus Information Technology, Wageningen, The Netherlands) using an image frequency of $4.2 /$ second. Raw data were transferred to Wintrack 2.4 (http://www.dpwolfer.ch/ wintrack) ${ }^{22}$ for off-line analysis. Statistical computations were done using Statview 5.0 (SAS Institute, Cary, NC).

\section{Fear Conditioning Test}

Auditory fear conditioning was performed by placing the mice in an opaque conditioning chamber $(\mathrm{L} \times \mathrm{W} \times \mathrm{H}$ : $25 \times 17 \times 23 \mathrm{~cm}$ ) with a grid floor through which scrambled foot shocks could be delivered as unconditioned stimuli (US; $0.26 \mathrm{~mA}$ average intensity). The chamber was placed into a dimly lit ( $<5$ lux) sound attenuating box (background noise level $55 \mathrm{~dB}$ ), and a speaker on top of the chamber allowed to deliver sounds as conditioning stimuli (CS; $2000 \mathrm{~Hz}$ ). The day before conditioning all mice were pre-exposed to the test chamber for 10 minutes. Animals were either submitted to a delay or trace fear conditioning session. Both sessions consisted of 1 minute adaptation period followed by five identical CS-US conditioning trials with 60 second intertrial intervals (ITI). In the delay fear conditioning each trial started with the presentation of the CS (15 seconds), and the US was presented during the last 2 seconds of the CS presentation. Trace fear conditioning was similar to delay protocol, except that each CS-US presentation was separated by an interval of 15 seconds. Twenty-four hours after training, in both protocols, mice were tested to the context and tone. To test conditioning to the context, mice were placed in the same experimental chamber for 2 minutes. To test conditioning to the tone animals were introduced to a new chamber with black/white walls and a solid-Plexiglas opaque floor, for 1 minute without CS (baseline), followed by 1 minute with the CS (tone). During the test, animals were video-tracked using the ANYmaze system. The frequency of freezing (absence of movements except respiration) was continuously recorded. Raw data were analyzed with the same program. Statistical computations were done using Statview 5.0 (SAS Institute). Hearing test was performed providing an unexpected sound to the mice kept in their own cage. A little jump of the mice following the sound is considered a positive response to the test. So the dependent variable analyzed is the presence or absence of the response.

\section{Polyribosome Analysis}

Polysomal profiles were performed as described previously. ${ }^{23}$ In brief, brains dissected free of cerebellum and bulbs were homogenized, using a glass douncer, in 10 $\mathrm{mmol} / \mathrm{L}$ HEPES-KOH pH 7.4, $150 \mathrm{mmol} / \mathrm{L} \mathrm{KCl,} 5 \mathrm{mmol} / \mathrm{L}$ $\mathrm{MgCl}_{2}, 0.5 \mathrm{mmol} / \mathrm{L} \mathrm{DTT}, 90 \mu \mathrm{g} / \mathrm{mL}$ cycloheximide, 0.03 $\mathrm{U} / \mu \mathrm{L}$ RNasin, $1 \mathrm{mmol} / \mathrm{L}$ PMSF, and 1:1000 protease inhibitor. The homogenized material was spun at $2000 \times g 10$ minutes at $4^{\circ} \mathrm{C}$, and NP-40 was added to the supernatant to 


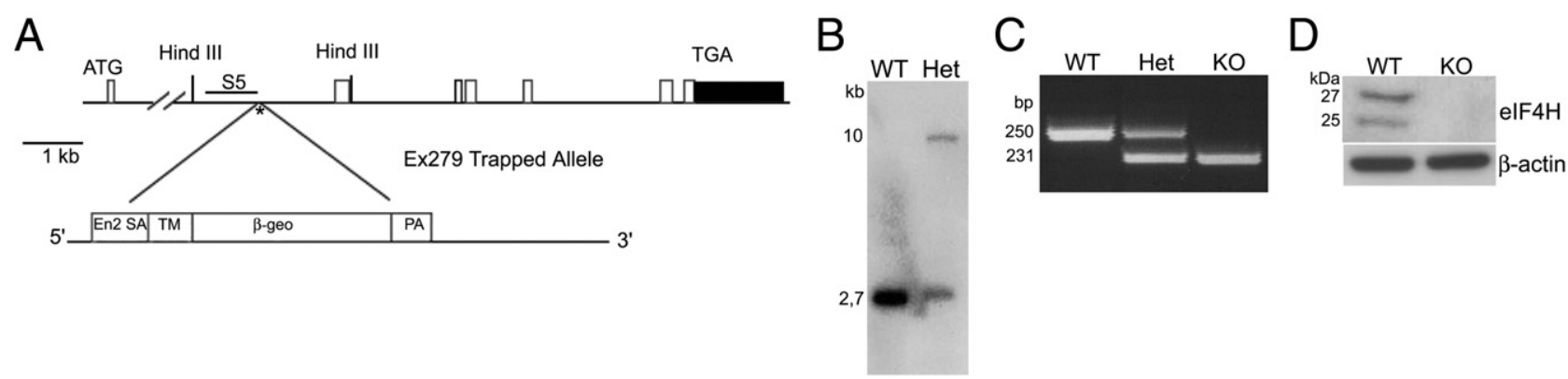

Figure 1. Generation of Eif4h mutant mice. A: The diagram shows the structure of the Eif4h trapped allele (Ex279), white boxes indicate exons, black box 3'UTR, and an asterisk marks the trap insertion site within the first intron of the gene. B: The trap insertion was determined by Southern blot. Genomic DNA was digested with HindIII and hybridized with the indicated probe (S5). A new restriction fragment of $10 \mathrm{~Kb}$ was detected in the heterozygous. C: Genotyping analysis by PCR. The wild-type allele gave a 250-bp band; the Eif4 $h^{(E X 279)}$ allele displayed a 231-bp product. D: Western blot with eIF4H antibody showed the absence of Eif $4 \mathrm{~h}$ proteins (27 and $25 \mathrm{kDa}$ ) in knockout MEF extracts. Het, heterozygous; KO, knockout; WT, wild type.

a final concentration of $1 \%$. After 5 minutes of incubation on ice, the material was spun at $20,000 \times g 10$ minutes at $4^{\circ} \mathrm{C}$, and $100 \mu \mathrm{g} / \mathrm{mL}$ heparin was added to the supernatant. The samples were loaded on $15 \%$ to $55 \%$ sucrose gradient, dissolved in $10 \mathrm{mmol} / \mathrm{L}$ HEPES-KOH pH 7.4, $150 \mathrm{mmol} / \mathrm{L} \mathrm{KCl,} 5$ $\mathrm{mmol} / \mathrm{L} \mathrm{MgCl}_{2}$. The gradients were centrifuged at $4^{\circ} \mathrm{C}$ for 3 hours and 30 minutes at 200,000 $\times g$ in a SW41Ti Beckman rotor. Absorbance at $254 \mathrm{~nm}$ was recorded by BioLogic LP software (Bio-Rad). Fractions of $0.25 \mathrm{~mL}$ volume were collected. The areas under the curve within the polysomal and subpolysomal fractions were estimated by weighing paper cut outs of the profiles.

\section{Results}

\section{Generation of Eif4h Null Mice}

An insertional mutation in the murine Eif4h gene was isolated in a gene-trap screen in mouse ES cells by BayGenomics. ${ }^{24}$ The trap vector contained a splice-acceptor sequence upstream of the reporter gene $\beta g e o$ that allowed the production of a fusion protein, including the first 20 amino acids encoded by the target gene and the reporter coding sequence (Figure 1A). The resulting ES clone Ex279 was injected into recipient blastocysts generating somatic chimeras that, crossed to C57Bl6 mice, gave germ-line transmission of the mutation. By Southern blot analysis we confirmed the insertion of the trapping cassette in the first intron of the Eif4h gene (Figure 1B). Specific primers, flanking the insertion site and within the gene-trap vector, were used for genotyping analysis by PCR (Figure 1C). Western blot on null embryonic fibroblasts (MEFs) showed the abrogation of Eif4h expression (Figure 1D). The expression levels of genes surrounding the Eif4h locus (Cyln2, Limk1, Gtf2l and Gtf2ird1) were not affected in knockout brains, as shown by real-time PCR (see Supplemental Figure S1, A-D, available at http:// ajp.amjpathol.org).

\section{Eif4h Expression Pattern in Adult Mouse Tissues and Brain}

Eif4h mRNA was detected in all organs and tissues analyzed by RT-PCR, high expression levels were revealed in muscle, testis, brain, and cerebellum (Figure 2A). In situ hybridization on sections of wild-type and knockout brains, with specific antisense riboprobes against Eif4h and Lacz respectively, showed the same expression pattern, as demonstrated by a representative midfrontal forebrain section (Figure 2B). X-Gal staining of knockout brains showed the Eif4h-driven lacZ expression in the olfactory bulbs and tubercle, cerebral, pyriform and entorhinal cortex, hippocampus, dentate gyrus, hypothalamus, cerebellum, and in other brain regions, including habenula and amygdala (Figure 2C). Localization of Eif4h proteins in subcellular fractions derived from wildtype cortical and subcortical brain regions was determined by Western blot. The analysis revealed the presence of the two expected bands of $27 \mathrm{kDa}$ and $25 \mathrm{kDa}$, in all of the assayed fractions, also at the synapses. AntiERK was used as control of the total proteins amount in each subcellular fraction, anti-synaptophysin (p38) and anti- $\beta$-tubulin as controls of the fractionating procedures (Figure 2D).

\section{Growth and Fertility Defects of Eif4h Null Mice}

Eif4h heterozygous mice were viable and fertile and offspring derived from inter heterozygous crosses were born in Mendelian ratios. On the other hand, knockout mice showed a reduced fertility. Eif4h ${ }^{-1-}$ males and females were regularly mated with wild-type animals over a period of 2 months. Females were daily checked for the presence of vaginal plug, as indication of sexual activity. We were unable to detect vaginal plugs in wild-type females mated with knockout males, whereas the knockout females were regularly plugged, but only a few of them (approximately $25 \%$ ) were pregnant and their litters never survived (Table 1). Adult Eif4h knockout mice visibly appeared smaller than controls. Because infantile growth deficiency occurs in WBS patients, we examined growth curves of male and female Eif4h mutants, from birth until 1 year old. The postnatal growth curves of wild types and knockouts started to diverge significantly 1 week after birth (males WT $=5.8 \pm 1.1 \mathrm{~g} ; \mathrm{KO}=4.4 \pm 0.8 \mathrm{~g}$ ) (females $\mathrm{WT}=$ $6.9 \pm 0.6 \mathrm{~g} ; \mathrm{KO}=5.1 \pm 0.6 \mathrm{~g}$ ) (Student's t-test, $P<0.001$ ). The weight gap persisted in adulthood, reaching its maximum of $30 \%$ to $35 \%$ around 6 months (males WT $=41.5 \pm 6.1 \mathrm{~g}$; $\mathrm{KO}=25.5 \pm 2.4 \mathrm{~g})($ females $\mathrm{WT}=28.5 \pm 3 \mathrm{~g} ; \mathrm{KO}=21 \pm$ 
A

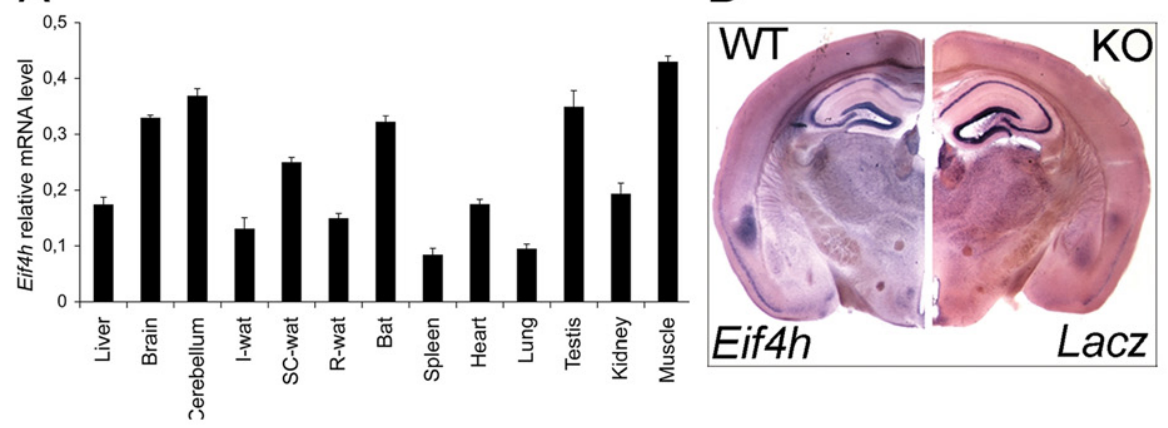

D

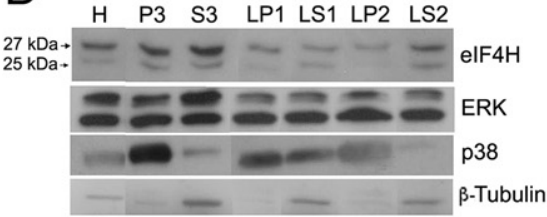

$\mathrm{C}$

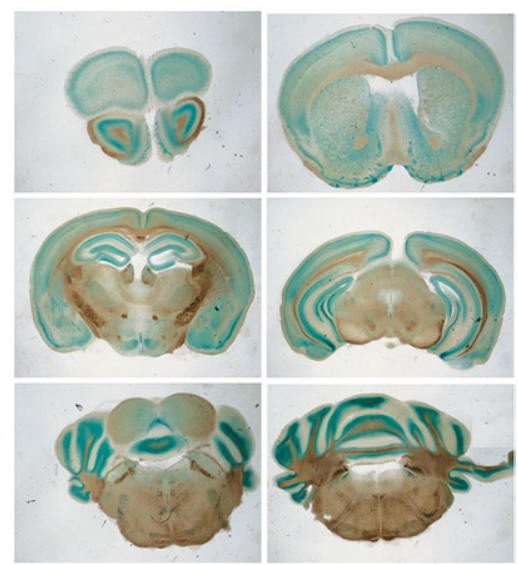

Figure 2. Eif 4 h expression pattern in adult mouse tissues and brain. A: Eif $4 \mathrm{~h}$ is differentially expressed in adult mouse organs and tissues. The relative amount of Eif $4 h$ transcripts, determined by quantitative real time PCR, were normalized against $\beta$-actin mRNA. Bat, brown adipose tissues; I-wat, inguinal-white adipose tissues; R-wat, retroperitoneal-wat; SC, subcutaneous-wat. Bars represent the average of triplicate measurements and error bars represent SD. B: In situ hybridization of WT (left) and KO brain (right) with antisense riboprobes against Eif 4 h and Lacz respectively, representative midfrontal forebrain sections. C: In adult Eif $4 h^{-1-}$ brain X-gal staining was detected in the olfactory bulbs and tubercle, cerebral, pyriform and entorhinal cortex, hippocampus, dentate gyrus, hypothalamus, and in other brain regions, including habenula, amygdala, and cerebellum. D: Western blot with eIF4H antibody on subcellular fractions derived from cortex and subcortical brain regions. ERK antibody was used as control of the total proteins amount in each subcellular fraction, anti-Synaptophysin (p38) and anti $\beta$-Tubulin as control of the fractionating procedures. Fractions are indicated above the lanes: $\mathrm{H}$ (total homogenate); $\mathrm{P} 3$ (cell body membranes); $\mathrm{S} 3$ (cytosol); LP1 (mitochondria and pre- and postsynaptic membranes); LS1 (total synaptosomal fraction); LP2 (synaptic vesicles); LS2 (synaptosol). The experiment was done in triplicate and the image of the immunoblot was the result of a montage from different gels.

$3.8 \mathrm{~g}$ ) (Student's t-test, $P<0.001)$. The growth curves of Eif4h heterozygous mice were shifted to those of wild-type animals (Figure 3, A and B). The lower body weight of Eif $4 h^{-1-}$ adults paralleled their shorter body length (males WT $=9.7 \pm 0.4 \mathrm{~cm}$; $\mathrm{KO}=8.9 \pm 0.3 \mathrm{~cm})($ females $\mathrm{WT}=9.4 \pm 0.4 \mathrm{~cm} ; \mathrm{KO}=8.6 \pm$ $0.3 \mathrm{~cm}$ ) (Student's t-test, $P<0.001$ ) (Figure 3, C and D). No growth abnormalities were evident during embryonic life (see Supplemental Figure S2 available at http://ajp.amjpathol.org). To understand if this growth deficit was equally distributed on total body mass, mice were sacrificed and organs and tissues were weighted. Almost all of them displayed lower weight in Eif4h ${ }^{-/-}$mice (Student's $t$-test, $P<0.001$ ), suggesting that knockout animals experienced a general growth deficit; in addition, there was a marked reduction of inguinal white adipose tissue, by around 70\% (Figure 3E). Remarkably, decreased body weight and reduced fat accumulation were not due to less food intake, which was comparable to control animals (3.8 $\pm 0.6 \mathrm{~g} /$ day) (Figure $3 \mathrm{~F})$. CT scan detected a

Table 1. Eif $4 h^{-/-}$Mice Display Reduced Fertility

\begin{tabular}{|c|c|c|c|c|c|}
\hline Crossing & $\begin{array}{c}\text { Male } \\
\times \\
\text { Female }\end{array}$ & $\begin{array}{c}\mathrm{KO} \\
\times \\
\mathrm{WT}\end{array}$ & $\begin{array}{c}\text { WT } \\
\times \\
\mathrm{KO}\end{array}$ & $\begin{array}{c}\text { Het } \\
\times \\
\text { WT }\end{array}$ & $\begin{array}{c}\text { Het } \\
\times \\
\text { Het }\end{array}$ \\
\hline Number of males mated & & 8 & 3 & 8 & 10 \\
\hline Number of females mated & & 16 & 6 & 8 & 10 \\
\hline Males producing plugs & & 0 & 3 & 8 & 10 \\
\hline Vaginal plugs observed & & 0 & 12 & 8 & 10 \\
\hline Delivering females & & 0 & 3 & 5 & 6 \\
\hline Average litter size & & - & 4 & 7.4 & 6.5 \\
\hline Littermates survived, \% & & - & 0 & 91 & 91.8 \\
\hline
\end{tabular}

Het, heterozygous mice; KO, knockout mice; WT, wild-type mice. significant volume reduction of knockout total body $(\mathrm{WT}=31.3$ $\pm 4.1 \mathrm{~cm}^{3} ; \mathrm{KO}=22.3 \pm 2.6 \mathrm{~cm}^{3}$ ) (Student's t-test, $P<0.001$ ), adipose tissues $\left(\mathrm{WT}=10.4 \pm 3.3 \mathrm{~cm}^{3} ; \mathrm{KO}=5.1 \pm 1.4 \mathrm{~cm}^{3}\right)$ (Student's t-test, $P<0.001)$, and muscle $\left(\mathrm{WT}=8.2 \pm 1.3 \mathrm{~cm}^{3}\right.$; $\mathrm{KO}=6.2 \pm 1.1 \mathrm{~cm}^{3}$ ) (Student's t-test, $P<0.01$ ) (Figure 4A). The volume of skeleton $\left(\mathrm{WT}=2.6 \pm 0.1 \mathrm{~cm}^{3} ; \mathrm{KO}=2.3 \pm 0.1\right.$ $\mathrm{cm}^{3}$ ) (Student's $t$-test, $\left.P<0.01\right)$ and skull $(\mathrm{WT}=0.66 \pm 0.02$ $\mathrm{cm}^{3} ; \mathrm{KO}=0.58 \pm 0,02 \mathrm{~cm}^{3}$ ) (Student's $t$-test, $P<0.001$ ) were also lower than in wild type (Figure 4B). Even if craniofacial abnormalities were not evident in knockout mice, we evaluated the presence of skull defects by measuring the distances between landmarks along the main axes (Figure 4C). Our mutants revealed a significant reduction in anteroposterior (WT $=2.32 \pm 0.05 \mathrm{~cm} ; \mathrm{KO}=2.27 \pm 0.04 \mathrm{~cm}$ ) and latero-lateral skull axes $(\mathrm{WT}=1.14 \pm 0.01 \mathrm{~cm} ; \mathrm{KO}=1.09 \pm 0.02 \mathrm{~cm})$ (Student's $t$-test, $P<0.001$ ), whereas no significant variations were evident in the nasal-zygomatic distance (Figure 4D). Postnatal growth deficiency, short stature, and craniofacial abnormalities have been also documented in individuals affected by Williams syndrome. ${ }^{25,26}$

\section{Volumetric Brain Analysis by MRl of Eif4h Knockout Mice}

In vivo high-resolution MRI was performed to investigate potential neuroanatomical anomalies present in adult knockout brains. Contiguous coronal T2-weighted images were acquired to measure the volumes of the brain and several selected structures (Figure 5A). This analysis revealed on average $12 \%$ whole brain volume reduction in knockout mice compared with wild type (WT $=481.7 \pm$ 
A

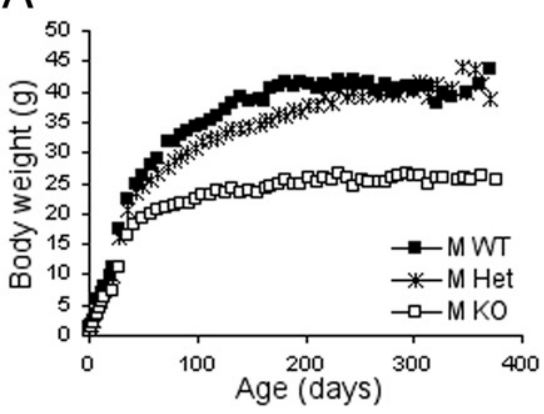

D

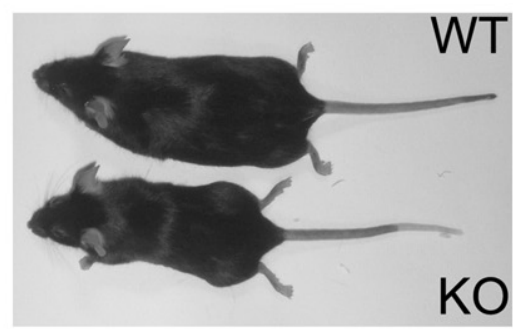

B

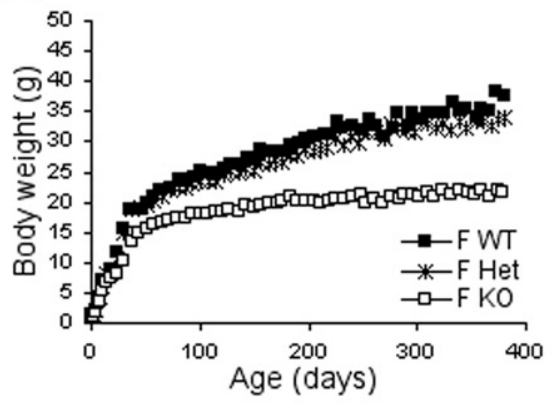

E

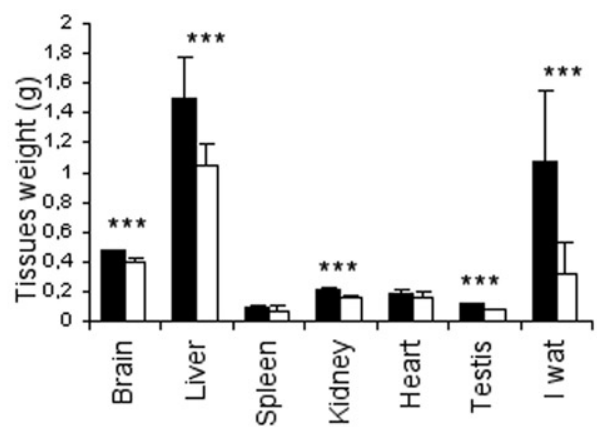

C

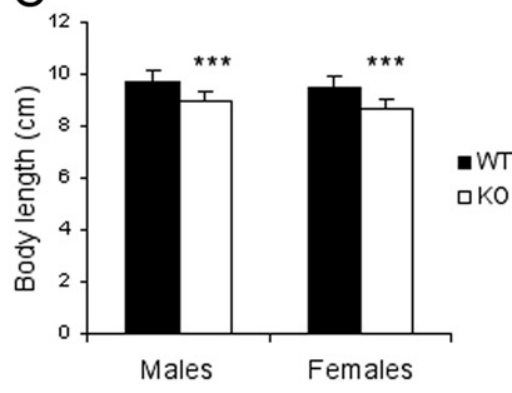

$\mathrm{F}$

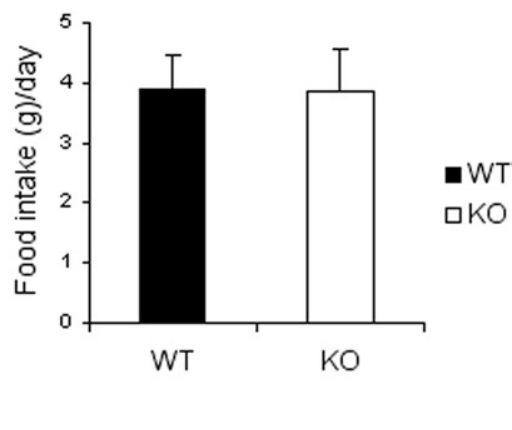

Figure 3. Postnatal growth retardation in Eif 4 h null mice. A and B: Growth curves of wild-type (WT) mice, solid squares; heterozygous mice (Het), asterisks; and KO mice, open squares; males $(n=17 \mathrm{WT}, 30 \mathrm{Het}, 22 \mathrm{KO})$ and females $(n=10 \mathrm{WT}, 23 \mathrm{Het}, 16 \mathrm{KO})$. C: Body length of Eif $4 h^{-1-}$ compared with WT, males $(n=21 \mathrm{WT}, 18 \mathrm{KO})$ and females $(n=13 \mathrm{WT}, 14 \mathrm{KO}) .{ }^{*}{ }^{\text {*op }} P<0.001$. D: Representative WT and Eif $4 b^{->-}$mice. E: Comparison of tissues weights between WT and null mice $(n=23 \mathrm{WT}, 21 \mathrm{KO})$. ${ }^{* * * *} P<0.001$. F: Food intake of KO and control mice indicated as g/day ( $n=25 \mathrm{WT}, 14 \mathrm{KO}$ ). Error bars represent SD. The statistical analysis was performed using the Student's $t$-test. Values of $P<0.05$ were considered significant.

$\left.11.7 \mathrm{~mm}^{3} ; \mathrm{KO}=425.5 \pm 29.6 \mathrm{~mm}^{3}\right)$ (Student's $t$-test, $P<$ $0.001)$. Looking separately at the cerebrum (CR), cerebellum (CB) and brainstem (BS), all of them displayed significant volume reductions (Student's $t$-test, CR $P<0.01$; $\mathrm{CB}$ and $\mathrm{BS} P<0.001$ ) (Figure 5B). In addition, the cerebrum volume was further analyzed in two selected regions along the anterior posterior axis, the former before the appearance of the hippocampus (anterior CR), the latter including it and posterior to it (posterior CR). Although the anterior cerebrum volumes were similar in both genotypes, mutant mice displayed a significant enlargement of lateral ventricles $\left(\mathrm{WT}=4.2 \pm 0.4 \mathrm{~mm}^{3} ; \mathrm{KO}=5.4 \pm 1.3 \mathrm{~mm}^{3}\right.$ )
A

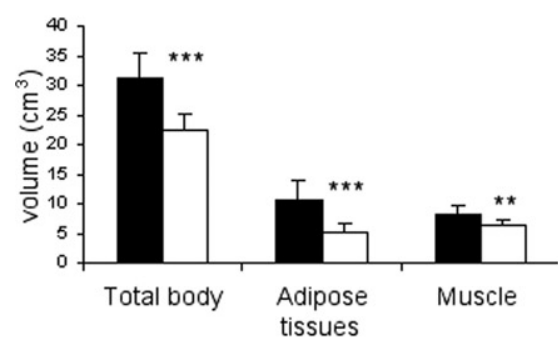

$\mathrm{D}$

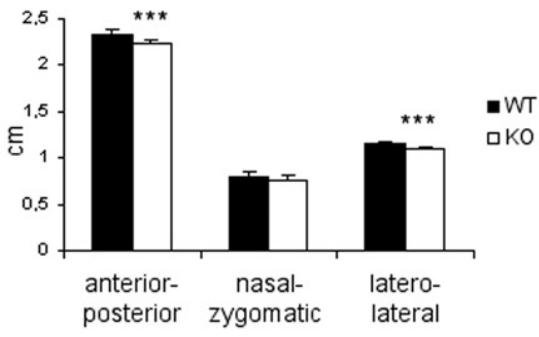

B

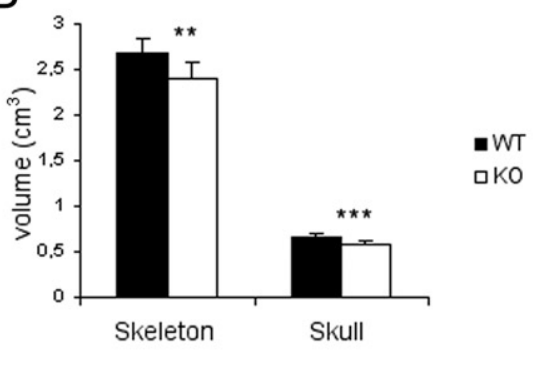

C

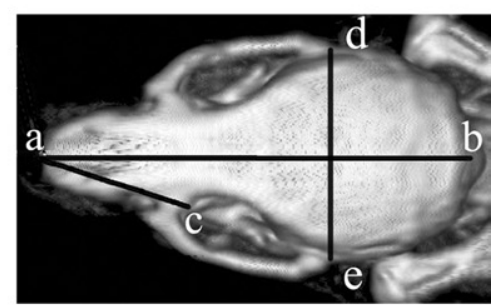

Figure 4. Computed tomography scan. A: Volumes of total body, adipose tissues, and muscle in wild-type (WT) and knockout mice (KO). ${ }^{* *} P<0.01 ;{ }^{* * *} P<0.001$. B: Volumes of skeleton and skull $(n=10 \mathrm{WT}, 9 \mathrm{KO}) .{ }^{* *} P<0.01 ;{ }^{* * * *} P<0.001$. C: Top view of the skull after three-dimensional reconstruction of CT images. The lines indicate the distances measured along the anteroposterior $(\mathbf{a}-\mathbf{b})$, the nasal-zygomatic $(\mathbf{a}-\mathbf{c})$, and latero-lateral $(\mathbf{d}-\mathbf{e})$ axis. D: Skull distances measured in WT and KO $(n=10 \mathrm{WT}, 9 \mathrm{KO}) .{ }^{* * *} P<0.001$. Error bars represent SD. The statistical analysis was performed using the Student's $t$-test. Values of $P<0.05$ were considered significant. 
A

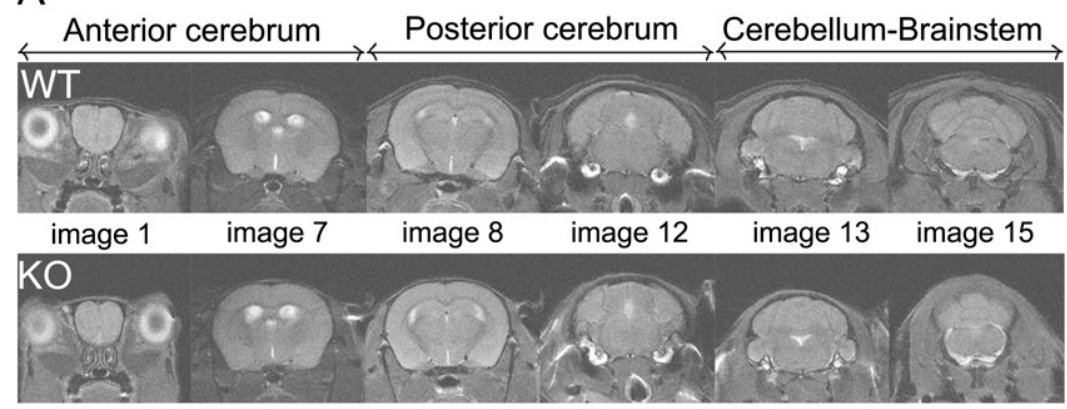

C

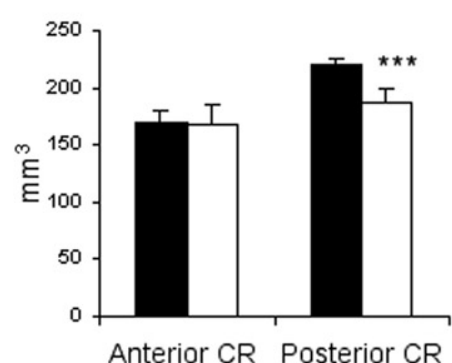

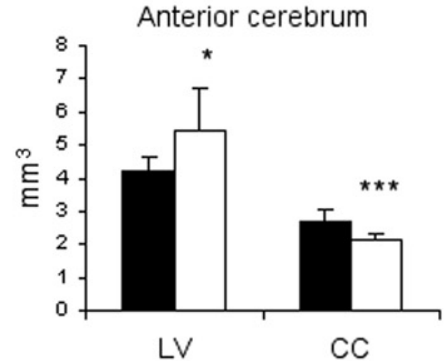

B
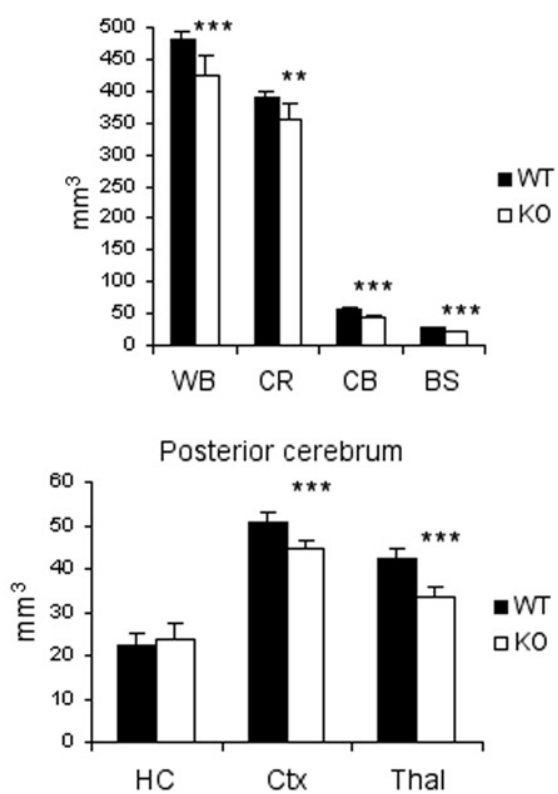

Figure 5. Brain MRI analysis. A: Typical T2-weighted images from wild-type (WT; upper panel) and Eif4h knockout mice (KO; lower panel). Fifteen contiguous coronal sections were acquired with a $0.85-\mathrm{mm}$ thickness. Volume of anterior cerebrum was calculated from the first to the seventh image, volume of posterior cerebrum from image 8 to 12 and volume of cerebellum and brainstem from image 13 to 15 . B: Volume measurement of whole brain and selected regions: WB, whole brain; $\mathrm{CR}$, cerebrum; CB, cerebellum; BS, brain stem. ${ }^{* *} P<0.01 ;{ }^{* * * *} P<0.001$. C: Volume measurements of the anterior and posterior cerebrum and respective selected structure: $\mathrm{LV}$, lateral ventricles; CC, corpus callosum; HC, hippocampus; Ctx, cortex; Thal, thalamic-hypothalamic nuclei. ${ }^{*} P<0.05$; ${ }^{* * * *} P<0.001$. $(n=7$ WT, $9 \mathrm{KO})$. Error bars represent SD. The statistical analysis was performed using the Student's $t$-test. Values of $P<0.05$ were considered significant.

(Student's t-test, $P<0.05)$ and a reduction of corpus callosum (WT $\left.=2.7 \pm 0.3 \mathrm{~mm}^{3} ; \mathrm{KO}=2.1 \pm 0.2 \mathrm{~mm}^{3}\right)($ Student's $t$-test, $P<0.001$ ). On the other hand, the volume of posterior cerebrum was significantly reduced in the knockout mice (Student's t-test, $P<0.001$ ). In particular, a drastic volume reduction was observed in posterior cortex (WT = $50.6 \pm 2.3 \mathrm{~mm}^{3} ; \mathrm{KO}=44.8 \pm 1.6 \mathrm{~mm}^{3}$ ), thalamic and hypothalamic nuclei (WT $=42.5 \pm 1.9 \mathrm{~mm}^{3} ; \mathrm{KO}=33.2 \pm$ $2.4 \mathrm{~mm}^{3}$ ) (Student's $t$-test, $P<0.001$ ), whereas the hippocampus size was preserved $\left(\mathrm{WT}=22.1 \pm 2.7 \mathrm{~mm}^{3}\right.$, $\mathrm{KO}=23.7 \pm 3.5 \mathrm{~mm}^{3}$ ) (Figure $5 \mathrm{C}$ ). Patients affected by WBS display alterations in cerebral shape ${ }^{27-30}$ with a reduction of total brain volume; a major decrease is present in the posterior cerebrum with a relative preservation of cerebellar volume ${ }^{31}$ and hippocampal size. ${ }^{32}$

\section{Neurons of the Posterior Cerebral Cortex Are Significantly Affected in Eif4h Knockout Brains}

The MRI data indicated that knockout mice displayed a significant reduction of posterior brain areas. Coronal sections of the posterior cortex (ie, visual cortex V1 to V2) from wild-type and knockout mice were analyzed for the expression of the neuron specific nuclear protein NeuN by immunohistochemistry. The $\mathrm{NeuN}^{+}$cells were significantly reduced in the cortex of mice lacking Eif4h (WT = $365.2 \pm 12.1 ; \mathrm{KO}=315.7 \pm 12.6$ ) (Student's $t$-test, $P<$ 0.05) (Figure 6, A and B). To assess whether the reduction of neurons, that we observed, was due to increasing rates of cell death, parallel sections were probed for the
TUNEL assay. No differences in dying cells were found between genotypes (see Supplemental Figure S3A available at $h$ ttp://ajp.amjpathol.org). Using the Golgi staining technique, we examined the effects of Eif4h inactivation on neuronal cell morphology. We measured dendritic complexity of cortical neuron by Sholl analysis. Data obtained revealed that branching was significantly reduced in mutant mice when compared with wild types (Student's t-test, $P<0.05$ ) (Figure 6, C and D). Eif4h knockout neurons compared to wild type also exhibited a significant reduction of the spine number (WT $=10.1 \pm 0.7 ; \mathrm{KO}=7 \pm$ 0.5 ) (Student's $t$-test, $P<0.01$ ) (Figure $6, \mathrm{E}$ and F). Finally we assayed the distribution of the myelin binding protein by immunohistochemistry. Accordingly with a reduction in the number of neurons, we also observed a slight alteration of myelin binding protein expression in the posterior cortical plate of null brains (see Supplemental Figure S3B, available at $h$ ttp://ajp.amjpathol.org).

\section{Eif4h Null Mice Show Normal Motor Coordination but Are More Prone to Muscular Fatigue}

Eif4h knockout mice were evaluated for motor coordination and muscular fatigue on three rota-rod tests. In the accelerating rota-rod protocol, test 1 , the average of all trials showed no significant differences between genotypes [analysis of variance (ANOVA) genotype effect: $F(1,38)=3.620, P=0.064$ ] (Figure $7 A$ ). In constant speed rota-rod, 24 hours later, test 2, the average of all 
A

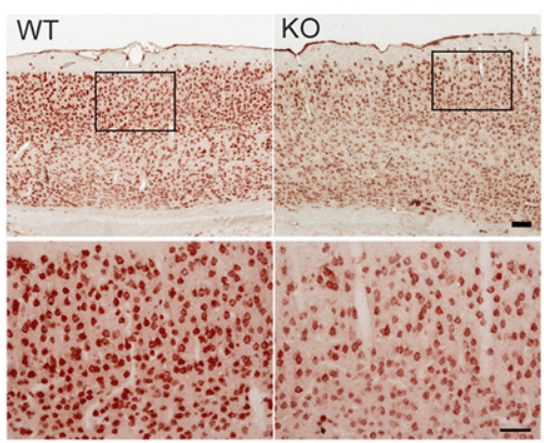

D

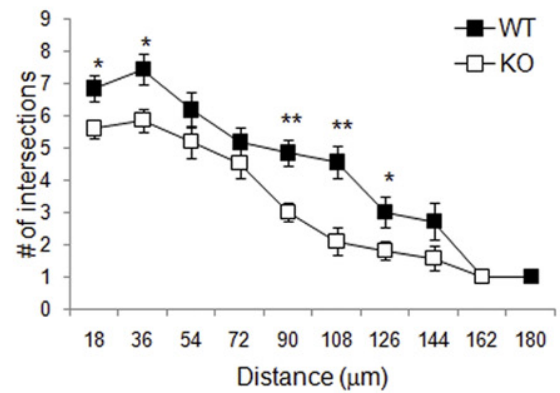

B

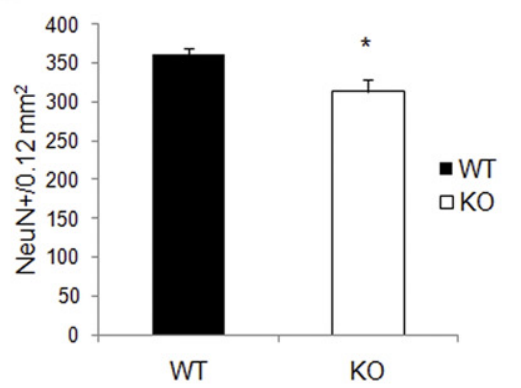

E

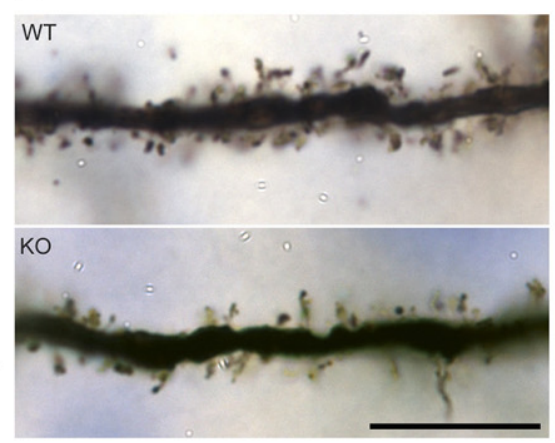

C

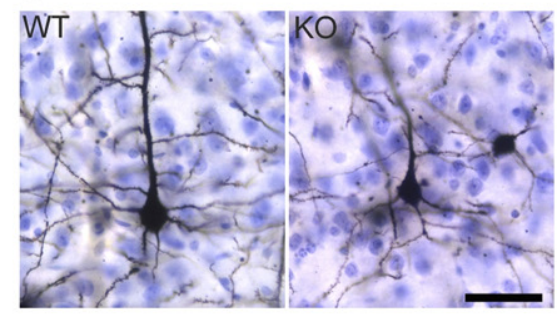

F

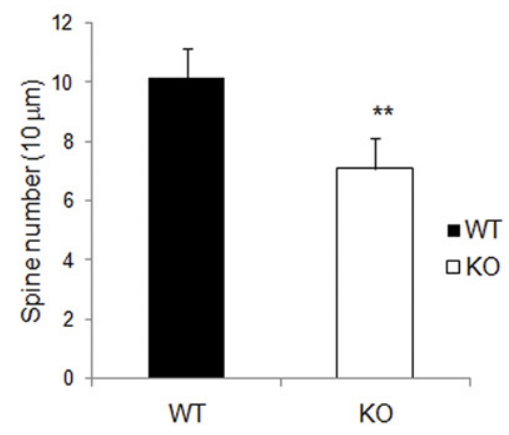

Figure 6. Immunohistological and morphological characterization of Eif $4 h$ knockout brains. A: NeuN immunostaining on representative sections of the posterior cortex of knockout $(\mathrm{KO})$ and wild-type (WT) brains. Original magnification $\times 4$, upper part; $\times 20$, of the lower part (from boxed area above). B: NeuN ${ }^{+}$cells were counted on four images of $0.12 \mathrm{~mm}^{2}(n=3 \mathrm{WT}, 3 \mathrm{KO}) .{ }^{*} P<0.05$. C: Example of Golgi-stained cortical neuron (original magnification $\left.\times 20\right)$. D: Sholl analysis illustrating differences in dendritic complexity. The values are the average of 12 neurons for each genotype $(n=3 \mathrm{WT}, 3 \mathrm{KO})$. ${ }^{*} P<0.05$, ${ }^{* *} P<0.01$. E: Golgi preparation showing dendrites from WT and KO (original magnification $\times 100$ ). F: Spine density $>10 \mu \mathrm{m}$ length. The values are the average of 15 dendrites for each genotype $(n=3 \mathrm{WT}, 3 \mathrm{KO}) .{ }^{* * * *} P<0.01$. Error bars represent SEM. The statistical analysis was performed using the Student's $t$-test. Values of $P$ $<0.05$ were considered significant. Scale bars $=50 \mu \mathrm{m}(\mathbf{A}$ and $\mathbf{C})$ and $10 \mu \mathrm{m}(\mathbf{E})$.

trials showed no significant differences between genotypes [ANOVA genotype effect: $F(1,38)=0.325, P=$ 0.571] (Figure 7B). In the test 3, we evaluated mouse performance on the rota-rod apparatus in five consecutive trials of 10 minutes each. Under these conditions null mice did not improve their performance as wild type did and significant differences between genotypes were observed [ANOVA genotype effect: $F(1,38)=4.547, P=$ 0.0395] (Figure 7C). These data suggested that Eif4h knockout mice showed normal motor coordination but they were more prone to muscular fatigue when the task was more demanding.

\section{Eif4h Null Mice Show Intact Emotional and Explorative Behavior, but Novelty Induces Hyperreactivity}

Emotional and explorative behavior of Eif4h knockout mice was analyzed by comparing three exploration
A

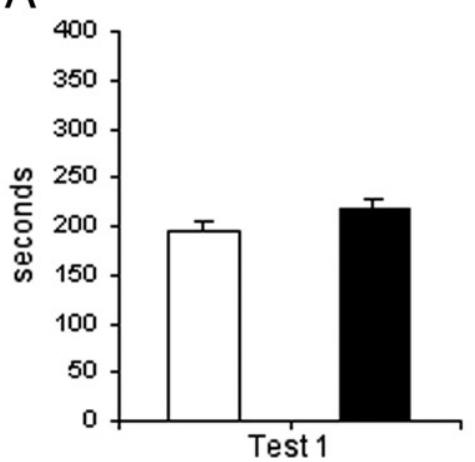

B

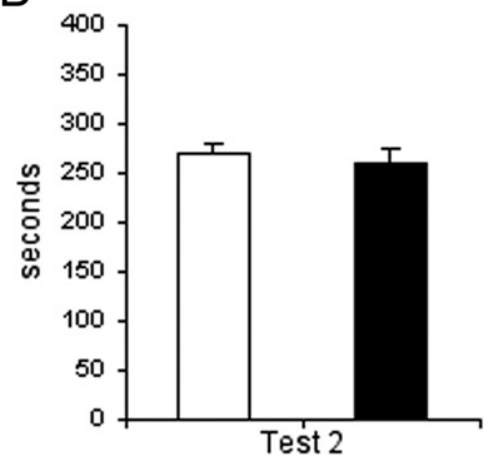

C

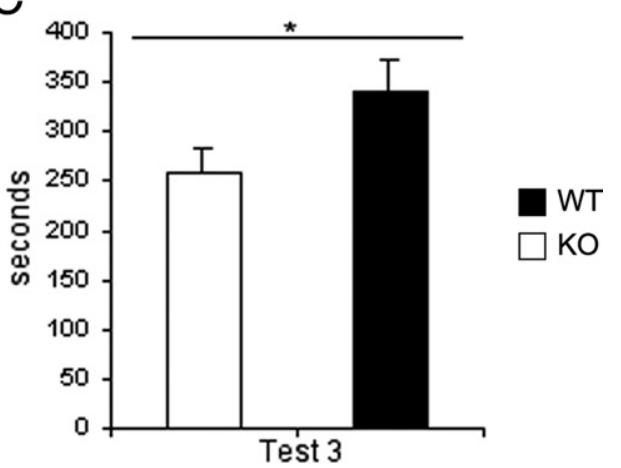

Figure 7. Rota-rod test. Wild-type (WT) and knockout mice (KO) were tested by accelerating rota-rod test 5 minutes. (A: Test 1 ), constant speed rota-rod test 5 minutes (B; Test 2 ), and rota-rod test 10 minutes $\left(\mathbf{C}\right.$; Test 3 ). The results were the average of five consecutive trials. ${ }^{*} P<0.05$. Error bars represent SEM. Statistical computations were done using Statview 5.0. Values of $P<0.05$ were considered significant. 

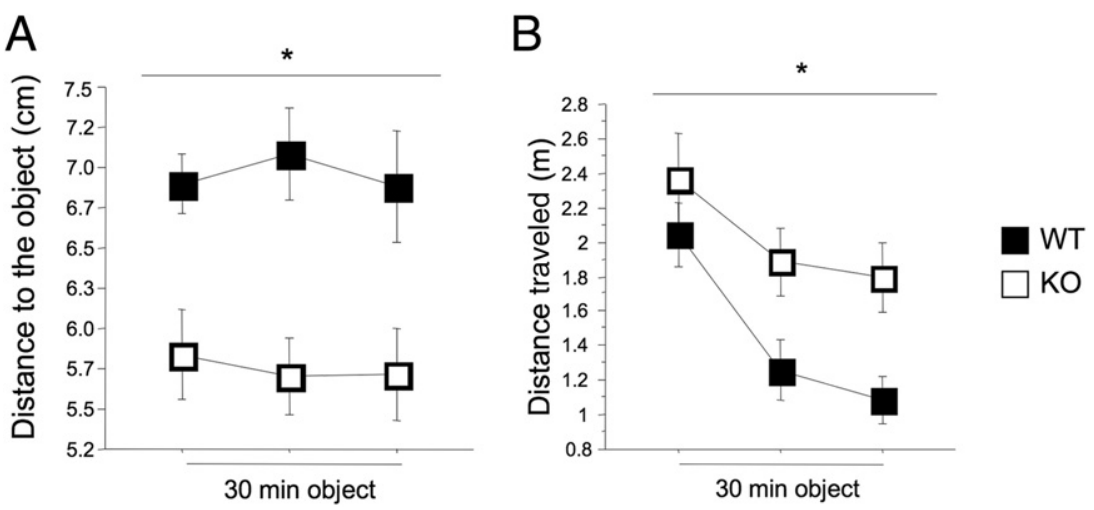

\begin{abstract}
Figure 8. Novelty test. A: Distance to the object of wild-type (WT) and knockout (KO) mice $(n=20$ WT, $20 \mathrm{KO}) .{ }^{*} P<0.05$. B: Locomotor activity: distance traveled when the novel object was introduced in the center of the arena. ${ }^{*} P<0.05$. Statistical computations were done using Statview 5.0. Values of $P$ $<0.05$ were considered significant
\end{abstract}

tests: the light-dark box, the emergence, and the novelty tests. ${ }^{33,34}$ No differences were observed between genotypes for variables assessing anxiety-like behavior, such us the time spent in the dark compartment in the light-dark test [ANOVA genotype effect: $F(1,38)=$ $0.547, P=0.464]$ and the time spent in the home box in the emergence test [ANOVA genotype effect: $F(1,38)=1.211, P=0.278]$. Moreover, in all tests no differences were observed for the distance traveled [dark light ANOVA genotype effect: $F(1,38)=1.449$, $P=0.236$; emergence ANOVA genotype effect: $F(1,38)=1.880, P=0.178$; novelty first 30 minutes ANOVA genotype effect: $F(1,38)=1.341, P=0.254$ ] and for the speed [dark light ANOVA genotype effect: $F(1,25)=0.102, P=0.751$; emergence ANOVA genotype effect: $F(1,38)=1.333, P=0.255$; novelty first 30 minutes ANOVA genotype effect: $F(1,38)=2.57, P=$ $0.1172]$. These data indicated that Eif $4 h^{-/-}$did not show deficits in anxiety-related and explorative behaviors and displayed normal spontaneous locomotor activity, in agreement with the normal motor coordination previously observed in the rota-rod test. In the novelty test, during the second part (30 minutes), the introduction of a novel object into the center of the arena induced the mutant mice to approach and investigate more the new object as measured by the distance to the object [ANOVA genotype effect for distance to the object: $F(1,16)=5.720, P=0.029$ ] (Figure 8A), and by the significant increase in locomotor activity [ANOVA genotype effect: $F(1,38)=4.896, P=0.033$ ] (Figure $8 \mathrm{~B})$. These results suggested that novelty induced hyperreactivity behavior in Eif4h knockout mice.

\section{Eif4h Knockout Display an Inability To Develop Efficient Spatial Memory}

In the water maze spatial reference memory task, Eif4h knockout mice showed a significant reduction in the swimming speed [ANOVA genotype effect: $F(1,38)=$ 123.725, $P<0.0001$ ] and a significant increase in floating [ANOVA genotype effect: $F(1,38)=6.651, P=$ 0.0139 ] and wall hugging time [ANOVA genotype effect: $F(1,38)=7.288, P=0.0103]$. The reduced swimming speed could account for the higher escape latency of knockouts [ANOVA genotype effect: $F(1,38)=$
26.632, $P<$ 0.0001] (Figure 9, A and B). However, during the acquisition phase the distance swum was similar in both genotypes [ANOVA genotype effect: $F(1,38)=0.293, P=0.5918]$, whereas in the reversal phase was significant longer in knockouts compared with wild types [ANOVA genotype effect: $F(1,38)=$ $6.720, P<0.013]$. Eif4h null mice were also less efficient in straightforward swimming to the goal as revealed by the analysis of the path efficiency [ANOVA genotype effect: $F(1,38)=16.665, P=0.0002]$. During the probe trial, control and mutant mice showed a preference for the trained goal quadrant (up to 25\%) compared with the three control zones [ANOVA genotype effect: $F(1,37)=1.377, P=0.248$ ] (Figure 9C), but knockout mice were less efficient in the annulus crossing [ANOVA genotype effect: $F(1,38)=18.321$, $P=0.0001]$ (Figure 9D). These findings suggested that Eif4h knockout mice had impairment in motor and motivation abilities to solve the task, probably due to a stress-related response to the water. However Eif4h null mice displayed an inability to develop an efficient spatial memory because they were able to learn the task, but were less efficient in finding the goal. To exclude possible visual defects, mice were tested in the visible platform version of the water maze. Even if a reduced swimming speed was observed in knockout mice, $100 \%$ of them were able to reach the flagged platform on average in 12 seconds.

\section{Eif4h Deletion Affects Associative Memory as Assessed by Fear Conditioning}

We used auditory fear conditioning to assess associative learning in Eif4h ${ }^{-1-}$ and wild-type mice. In this task the animals developed an immobility response (freezing) after exposure to tones (conditioning stimulus, CS) paired with foot-shocks (unconditioned stimulus, US). Animals were subjected to two different protocols: in the delay fear conditioning there was a CS-US temporal overlap and their association mainly depends on the amygdala activity. In the trace procedure a time interval was introduced between the two stimuli, as previously described, ${ }^{35}$ in this case the CS-US association involves different brain 
A

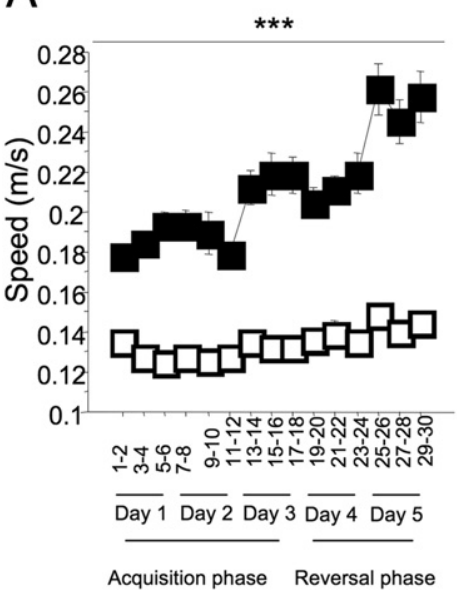

C

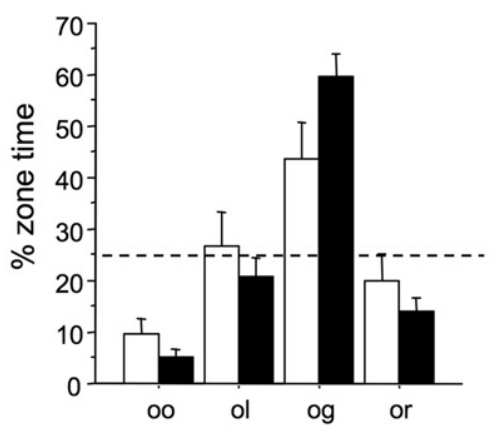

B

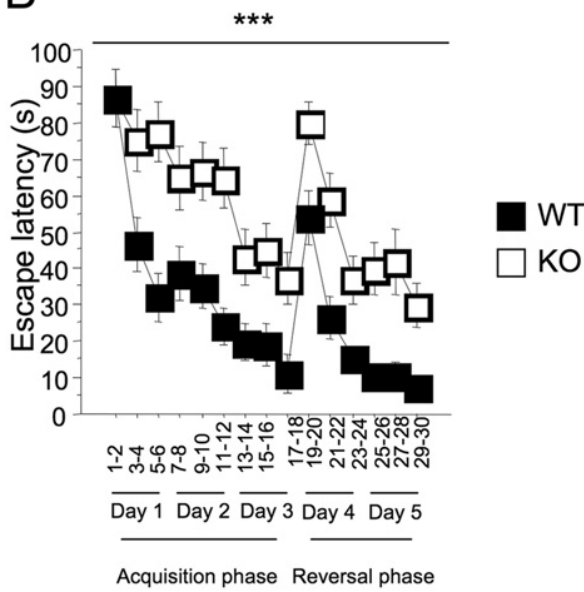

D

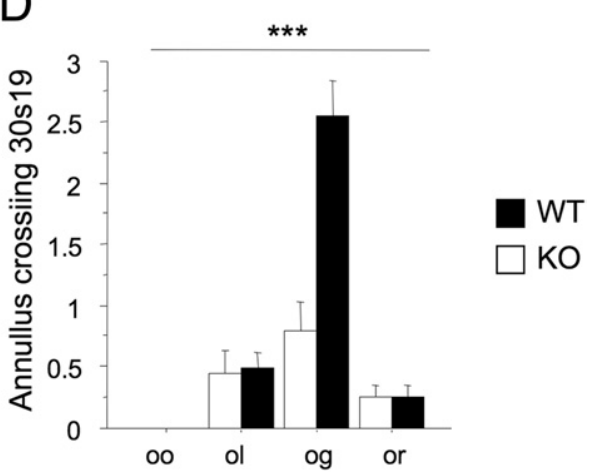

Figure 9. Morris water maze test. A: Swimming speed of wild-type (WT) and knockout mice (KO) during the task $(n=20 \mathrm{WT}, 20 \mathrm{KO}) .{ }^{* * * *} P<$ 0.001. B: Learning curve indicating the time required to reach the hidden platform (escape latency expressed in seconds) over 5 days. ${ }^{* * *} P<$ 0.001. C: Percentage of time spent in the four quadrants during the probe trial. Dashed line represents the $25 \%$ chance level of swimming in that particular zone. D: Annulus crossing measured during the probe trial. Old goal $(\mathrm{og})$ indicates the old platform position, old opposite (oo) the new opposite position of the platform, old left (ol) and old right (or) the quadrant at the left and at the right of the old goal, respectively. ${ }_{* * * *} P<0.001$. Statistical computations were done using Statview 5.0. Values of $P<0.05$ were considered significant. regions as the hippocampus and prefrontal cortex. ${ }^{36}$ In both protocols, the percentage of freezing over the five tone presentations increased in control animals. This did not happen in Eif4h knockouts, which showed a significant lower freezing percentage throughout the conditioning sessions [ANOVA genotype effect in trace fear conditioning: $F(1,34)=76.9, P<0.0001$; genotype effect in delay fear conditioning: $F(1,38)=28.5, P<0.0001$ ] (Figure 10, A and D). In delay as well as in trace fear conditioning significant differences were also observed between genotypes when 24 hours later animals were tested for freezing reactions to the context and tone. Context testing consisted of 2 minutes in the same experimental chamber without CS [genotype effect in trace fear conditioning: $F(1,34)=20.4, P<0.0001$; genotype effect in delay fear conditioning: $F(1,38)=7.68$, $P=0.0086$ ] (Figure 10, B and E). Tone testing consisted of 1 minute in a new context without CS (baseline), followed by 1 minute with the CS turned on (tone) [genotype effect in trace fear conditioning: $>F(1,34)=15.8, P=$ 0.0004 ; genotype effect in delay fear conditioning: $F(1,38)=52.1, P<0.0001$ ] (Figure 10, $C$ and $F$ ). All together these data suggested that Eif4h mutant mice were severely impaired in associative fear-related memory formation. No differences were observed in mutants compared with the control mice for the hearing an unexpected stimulus (sound), suggesting that the reported memory defects were not due to deafness.

\section{Global Process of Translation Is Not Affected in Eif4h Knockout Mice}

To evaluate if the specific phenotypes described for Eif4h knockout mice were associated with deficits in the control of global protein synthesis, we analyzed polysomal profiles of wild-type and Eif4h knockout brains. Fractions were collected and the absorbance was continuously monitored at $254 \mathrm{~nm}$. The polysomal profiles did not present significant differences between genotypes, as confirmed by comparable percentages of the area under the polysomal $(\mathrm{WT}=19 \% \pm 1.4 ; \mathrm{KO}=18 \% \pm 1.5)$ and subpolysomal (WT $=81 \% \pm 1.4 ; \mathrm{KO}=82 \% \pm 1.5$ ) fractions (Figure 11). These results indicated that the absence of Eif4h did not impair the global process of translation and initiation.

\section{Discussion}

We described the generation of a new mouse line carrying a null allele for Eif4h, which encodes a factor involved in the initiation phase of protein synthesis. ${ }^{37}$ The human homolog of this gene, WBSCR1, is located within a region commonly deleted in WBS patients, the Williams-Beuren Syndrome critical region. The WBS is a complex neurodevelopmental disorder consequence of multiple gene deletions. WBS patients display abnormalities in devel- 
A

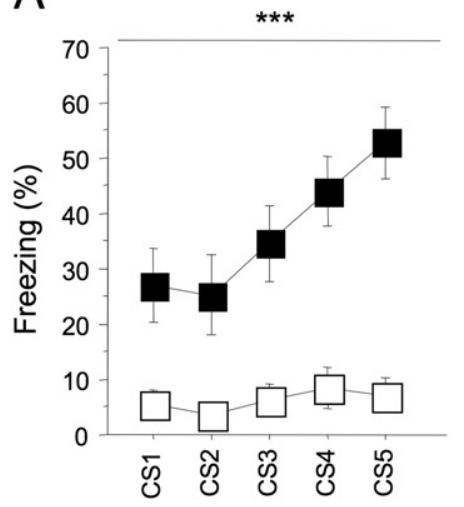

$\mathrm{D}$

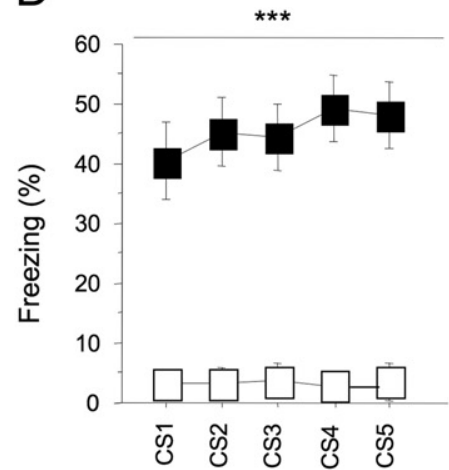

B
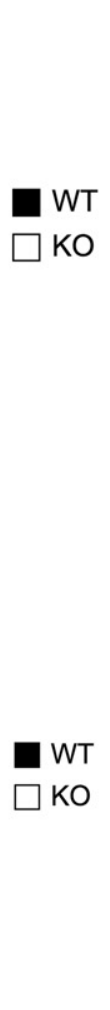

E
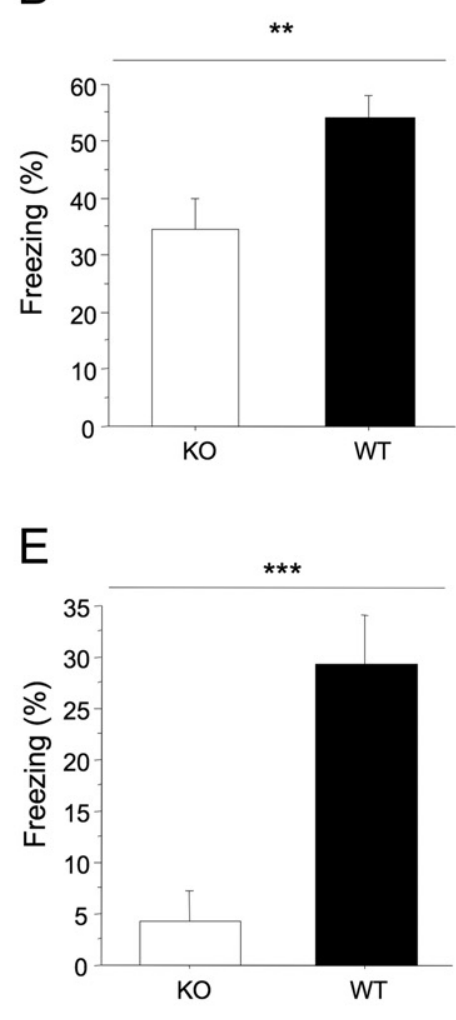

C

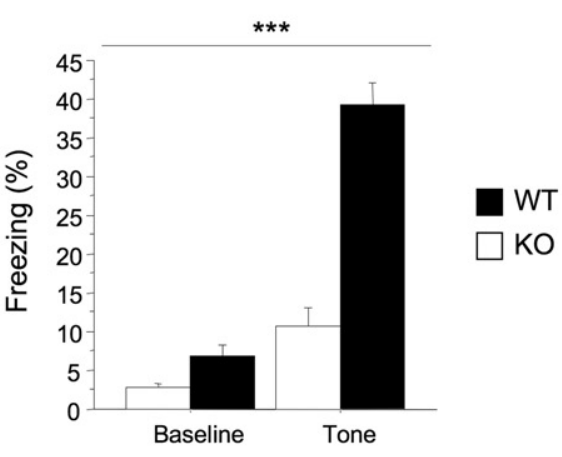

$\mathrm{F}$

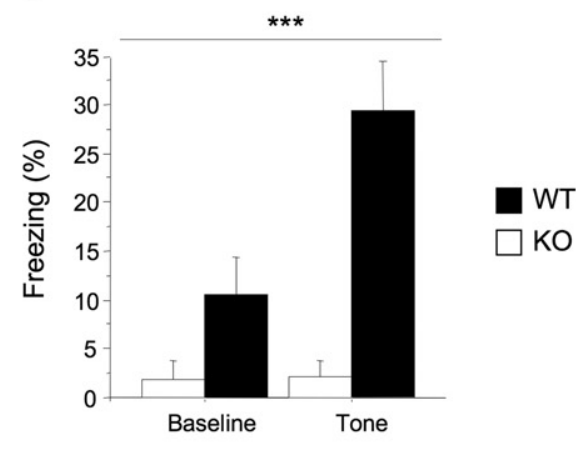

Figure 10. Fear conditioning tasks. Wild-type (WT) and knockout mice (KO) ( $n=20$ WT, 20 KO) were subjected to two different protocols: delay (A-C) and trace (D-F) fear conditioning. A and D: Percentage of freezing during the training sessions. ${ }^{* * *} P<0.001$. B and $\mathbf{E}$ : Percentage of freezing during the context test, 24 hours later. ${ }^{* *} P<0.01 ;{ }^{* * *} P<0.001$. C and F: Percentage of freezing during the tone test, 24 hours later. Baseline indicated the period without tone. ${ }^{* * * *} P<$ 0.001. Statistical computations were done using Statview 5.0. Values of $P<0.05$ were considered significant.

opment, growth and structure of internal organs, as well as a unique neurocognitive profile. ${ }^{38}$ Although mice carrying a single gene deletion may only partially recapitulate the complex phenotype occurring to WBS patients, the analysis of the Eif4h mutant mice that we have provided, support a contribution of Eif4h to the syndrome. Indeed, the absence of Eif4h resulted in growth deficits, brain abnormalities, altered neuronal morphology, and specific behavioral impairments that overlap with some aspects of the phenotype observed in patients. Growth defects occurring in Eif4h null mice clearly indicated that Eif4h is necessary for proper mouse development and brain morphology alterations, revealed by in vivo MRI analysis, resembled those observed in WBS patients. It will be interesting to understand whether are these brain abnormalities due to abnormal development, do they reflect insufficiency of Eif4h function in the adult, or both. Moreover the absence of Eif4h strongly affected fearrelated learning and associative memory formation and suggested a possibly impairment of hippocampal and amygdala circuits in null mice. We can hypothesize that the hippocampal circuits dysfunctions, found in knockout mice, were not due to loss of volume but rather to functional impairments of this region. Even in WBS patients $\mathrm{MRI}$ showed normal volume of hippocampal structure in contrast to marked functional changes. ${ }^{32}$ In conclusion, Eif4h may contribute to several phenotypic and structural aspects of the Williams-Beuren syndrome as well as to its
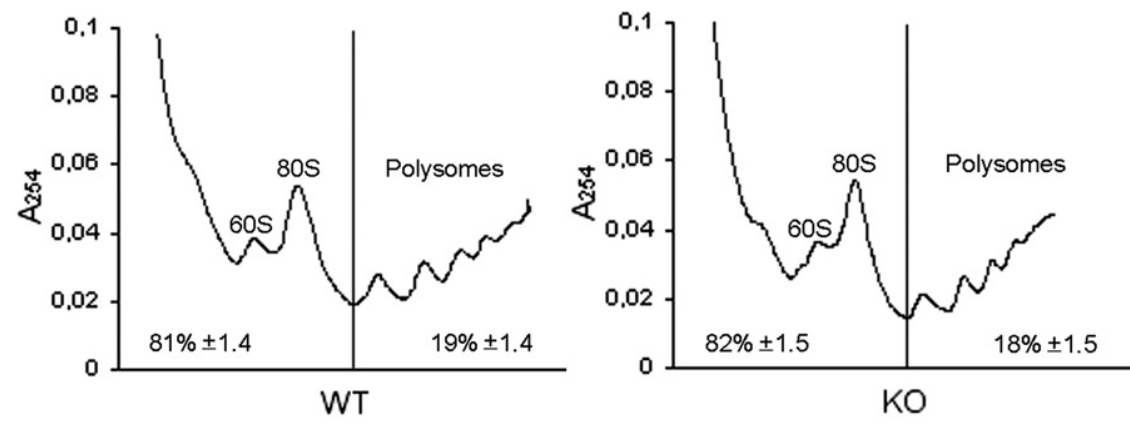

Figure 11. Analysis of global protein synthesis Polysomal profile from wild-type (WT) and knockout mouse (KO) brain extracts. The vertical line separates the polysomal fraction (right) and the subpolysomal fraction (left). The percentages indicated the proportion of the area under the curves and represented the mean \pm $\mathrm{SD}$ of $6 \mathrm{WT}$ and $6 \mathrm{KO}$ independent profiles. 
particular cognitive and behavioral profile. Eif4h cooperates with the helicase elF4A in the initiation phase of protein synthesis. The protein synthesis is well established to play an important role in synaptic plasticity, memory, learning, development, and differentiation. It has been implicated in a variety of human diseases $3,39,40$ and subtle changes in the initiation step of this process could account for deep consequences in development, growth, and brain functions. We showed that Eif4h proteins were present in all brain subcellular fractions, including synapses, suggesting that this gene may play a role in the regulation of local translation of specific mRNAs. Moreover, based on the results of several lines of research, it has been proposed that alteration in synaptic protein synthesis is one possible pathway underling several intellectual disabilities as mental retardation or autistic phenotypes. ${ }^{41}$ Abnormalities in dendritic complexity and spine density, observed in Eif4h null mice, are also found in other disorders related to the central nervous system. In this light the Eif4h mutant line may represent a new useful animal model related to Williams Beuren syndrome and also to the heterogeneous group of neurodevelopmental pathologies termed autism spectrum disorders. Genome-wide analysis of mRNAs or protein expression in Eif4h mutant mice will be necessary to identify molecules and pathways that may be either directly or indirectly altered in absence of this gene.

\section{Acknowledgments}

We thank Dr. Valentina Gandin for her kind help with the polysomal profiles and Dr. Flavia Valtorta for the p38 antibody.

\section{References}

1. Gingras AC, Raught B, Sonenberg N: elF4 initiation factors: effectors of $m R N A$ recruitment to ribosomes and regulators of translation. Annu Rev Biochem 1999, 68:913-963

2. Hernandez G, Vazquez-Pianzola P: Functional diversity of the eukaryotic translation initiation factors belonging to elF4 families. Mech Dev 2005, 122:865-876

3. Sonenberg N, Hinnebusch AG: Regulation of translation initiation in eukaryotes: mechanisms and biological targets. Cell 2009, 136:731745

4. Richter NJ, Rogers GW, Jr., Hensold JO, Merrick WC: Further biochemical and kinetic characterization of human eukaryotic initiation factor 4H. J Biol Chem 1999, 274:35415-35424

5. Rogers GW, Jr., Richter NJ, Lima WF, Merrick WC: Modulation of the helicase activity of elF4A by elF4B, elF4H, and elF4F. J Biol Chem 2001, 276:30914-30922

6. Rogers GW Jr, Richter NJ, Merrick WC: Biochemical and kinetic characterization of the RNA helicase activity of eukaryotic initiation factor 4A. J Biol Chem 1999, 274:12236-12244

7. Bayes M, Magano LF, Rivera N, Flores R, Perez Jurado LA: Mutational mechanisms of Williams-Beuren syndrome deletions. Am J Hum Genet 2003, 73:131-151

8. Peoples R, Franke Y, Wang YK, Perez-Jurado L, Paperna T, Cisco M, Francke $U$ : A physical map, including a BAC/PAC clone contig, of the Williams-Beuren syndrome-deletion region at 7q11.23. Am J Hum Genet 2000, 66:47-68

9. Francke U: Williams-Beuren syndrome: genes and mechanisms. Hum Mol Genet 1999, 8:1947-1954
10. Meyer-Lindenberg A, Mervis CB, Berman KF: Neural mechanisms in Williams syndrome: a unique window to genetic influences on cognition and behaviour. Nat Rev Neurosci 2006, 7:380-393

11. Pober BR: Williams-Beuren syndrome. N Engl J Med 2010, 362:239252

12. Tassabehji M: Williams-Beuren syndrome: a challenge for genotypephenotype correlations. Hum Mol Genet 2003, 12(Spec No 2):R229 R237

13. Stromme P, Bjornstad PG, Ramstad K: Prevalence estimation of Williams syndrome. J Child Neurol 2002, 17:269-271

14. DeSilva U, Elnitski L, Idol JR, Doyle JL, Gan W, Thomas JW, Schwartz S, Dietrich NL, Beckstrom-Sternberg SM, McDowell JC, Blakesley RW, Bouffard GG, Thomas PJ, Touchman JW, Miller W, Green ED: Generation and comparative analysis of approximately 3.3 Mb of mouse genomic sequence orthologous to the region of human chromosome 7q11.23 implicated in Williams syndrome. Genome Res 2002, 12:3-15

15. Osborne LR: Animal models of Williams syndrome. Am J Med Genet C Semin Med Genet 2010, 154C:209-219

16. Ewart AK, Morris CA, Atkinson D, Jin W, Sternes K, Spallone P, Stock AD, Leppert M, Keating MT: Hemizygosity at the elastin locus in a developmental disorder. Williams syndrome. Nat Genet 1993, 5:11-16

17. Valtorta F, Jahn R, Fesce R, Greengard P, Ceccarelli B: Synaptophy$\sin (p 38)$ at the frog neuromuscular junction: its incorporation into the axolemma and recycling after intense quantal secretion. J Cell Biol 1988, 107:2717-2727

18. Centonze D, Muzio L, Rossi S, Cavasinni F, De Chiara V, Bergami A, Musella A, D'Amelio M, Cavallucci V, Martorana A, Bergamaschi A, Cencioni MT, Diamantini A, Butti E, Comi G, Bernardi G, Cecconi F, Battistini L, Furlan R, Martino G: Inflammation triggers synaptic alteration and degeneration in experimental autoimmune encephalomyelitis. J Neurosci 2009, 29:3442-3452

19. Lipp HP, Wolfer DP: Genetically modified mice and cognition. Curr Opin Neurobiol 1998, 8:272-280

20. Morris RG, Garrud P, Rawlins JN, O'Keefe J: Place navigation impaired in rats with hippocampal lesions. Nature 1982, 297:681-683

21. Morris R: Developments of a water-maze procedure for studying spatial learning in the rat. J Neurosci Methods 1984, 11:47-60

22. Wolfer DP, Lipp HP: A new computer program for detailed off-line analysis of swimming navigation in the Morris water maze. J Neurosci Methods 1992, 41:65-74

23. Stefani G, Fraser CE, Darnell JC, Darnell RB: Fragile X mental retardation protein is associated with translating polyribosomes in neuronal cells. J Neurosci 2004, 24:7272-7276

24. Skarnes WC, Moss JE, Hurtley SM, Beddington RS: Capturing genes encoding membrane and secreted proteins important for mouse development, Proc Natl Acad Sci USA: 1995, 92:6592-6596

25. Morris CA, Demsey SA, Leonard CO, Dilts C, Blackburn BL: Natural history of Williams syndrome: physical characteristics. J Pediatr 1988, 113:318-326

26. Pankau R, Partsch CJ, Gosch A, Oppermann HC, Wessel A: Statural growth in Williams-Beuren syndrome. Eur J Pediatr 1992, 151:751755

27. Reiss AL, Eckert MA, Rose FE, Karchemskiy A, Kesler S, Chang M, Reynolds MF, Kwon H, Galaburda A: An experiment of nature: brain anatomy parallels cognition and behavior in Williams syndrome. J Neurosci 2004, 24:5009-5015

28. Reiss AL, Eliez S, Schmitt JE, Straus E, Lai Z, Jones W, Bellugi U: IV. Neuroanatomy of Williams syndrome: a high-resolution MRI study. J Cogn Neurosci 2000, 12(Suppl 1):65-73

29. Schmitt JE, Eliez S, Bellugi U, Reiss AL: Analysis of cerebral shape in Williams syndrome. Arch Neurol 2001, 58:283-287

30. Jackowski AP, Rando K, Maria de Araujo C, Del Cole CG, Silva I, Tavares de Lacerda AL: Brain abnormalities in Williams syndrome: a review of structural and functional magnetic resonance imaging findings. Eur J Paediatr Neurol 2009, 13:305-316

31. Jernigan TL, Bellugi U, Sowell E, Doherty S, Hesselink JR: Cerebral morphologic distinctions between Williams and Down syndromes. Arch Neurol 1993, 50:186-191

32. Meyer-Lindenberg A, Mervis CB, Sarpal D, Koch P, Steele S, Kohn P, Marenco S, Morris CA, Das S, Kippenhan S, Mattay VS, Weinberger $\mathrm{DR}$, Berman KF: Functional, structural, and metabolic abnormalities 
of the hippocampal formation in Williams syndrome. J Clin Invest 2005, 115:1888-1895

33. Belzung C: Hippocampal mossy fibres: implication in novelty reactions or in anxiety behaviours? Behav Brain Res 1992, 51:149-155

34. Dulawa SC, Grandy DK, Low MJ, Paulus MP, Geyer MA: Dopamine D4 receptor-knock-out mice exhibit reduced exploration of novel stimuli. J Neurosci 1999, 19:9550-9556

35. D'Adamo P, Wolfer DP, Kopp C, Tobler I, Toniolo D, Lipp HP: Mice deficient for the synaptic vesicle protein Rab3a show impaired spatial reversal learning and increased explorative activity but none of the behavioral changes shown by mice deficient for the Rab3a regulator Gdi1. Eur J Neurosci 2004, 19:1895-1905

36. Raybuck JD, Lattal KM: Double dissociation of amygdala and hippocampal contributions to trace and delay fear conditioning. PLOS One 2011, 6:e15982
37. Richter-Cook NJ, Dever TE, Hensold JO, Merrick WC: Purification and characterization of a new eukaryotic protein translation factor. Eukaryotic initiation factor 4H. J Biol Chem 1998, 273:7579-7587

38. Bellugi U, Lichtenberger L, Jones W, Lai Z, St George M: I. The neurocognitive profile of Williams Syndrome: a complex pattern of strengths and weaknesses. J Cogn Neurosci 2000, 12(Suppl 1): 7-29

39. Costa-Mattioli M, Sossin WS, Klann E, Sonenberg N: Translational control of long-lasting synaptic plasticity and memory. Neuron 2009, 61:10-26

40. Sossin WS, Lacaille JC: Mechanisms of translational regulation in synaptic plasticity. Curr Opin Neurobiol 20:450-456

41. Kelleher RJ, 3rd, Bear MF: The autistic neuron: troubled translation? Cell 2008, 135:401-406 